\title{
Relevance of Formation Conditions on the Size, Morphology and Local Structure of Intrinsic Plutonium Colloids
}

Cyril Micheau, ${ }^{a}$ Matthieu Virot, ${ }^{{ }^{*}}$ Sandrine Dourdain, ${ }^{a}$ Thomas Dumas, ${ }^{b}$ Denis Menut, ${ }^{c}$ Pier Lorenzo Solari, ${ }^{c}$ Laurent Venault, ${ }^{b}$ Olivier Diat, ${ }^{a}$ Philippe Moisy, ${ }^{b}$ Sergey I. Nikitenko ${ }^{a}$

${ }^{a}$ ICSM, Univ Montpellier, UMR 5257, CEA, CNRS, ENSCM, Marcoule, France.

${ }^{\mathrm{b}} \mathrm{CEA}, \mathrm{DES}, \mathrm{ISEC}, \mathrm{DMRC}$, Univ Montpellier, Marcoule, France.

${ }^{c}$ Synchrotron SOLEIL, MARS beamline, l'Ormes des Merisiers, Saint Aubin BP 48, 91192 Gif-surYvette, France.

\section{Abstract}

Fundamental knowledge about plutonium intrinsic colloids is a key issue for the prediction of plutonium transport and release rates in the environment. Recent studies demonstrated that the particle size and surface properties of intrinsic Pu colloids are strongly influenced by the preparation method. In this work, a combination of synchrotron Small Angle X-ray Scattering (SAXS) with X-ray Absorption Spectroscopy (XAS) is used to characterize two kinds of stable plutonium intrinsic colloids prepared by hydrolysis of $\mathrm{Pu}(\mathrm{IV})$ ionic species and sonolysis of $\mathrm{PuO}_{2}$ in pure water. Despite their similarities, the multi-scale structural properties of these colloidal suspensions are found to be strongly influenced by the synthesis route. Hydrolysis approach leads to spherical nanoparticles of ca. $2.0 \mathrm{~nm}$ whereas sonolytic colloids show elongated structures measuring $5.7 \mathrm{~nm}$ of thickness and $>30 \mathrm{~nm}$ long. This difference results from the synthesis mechanism and can be attributed to nanoparticle aggregation in the absence of capping-ions. The results obtained by both SAXS and XAS approaches converge in the description of $\mathrm{Pu}(\mathrm{IV})$ intrinsic colloids as core-shell nanoparticles made up of a $\mathrm{PuO}_{2}$ core covered with a disordered $\mathrm{Pu}-\mathrm{O}$ shell characterized by a splitting of Pu-O and Pu-Pu distances and an associated strong increase of associated DWF parameters. The local distortions of both Pu-O and Pu-Pu coordination spheres observed by XAS seems to be correlated with the nanoparticle shrinking probed by SAXS rather from the contribution of higher Pu oxidation states. The stabilization of the hydrolytic colloidal particles is further suggested from SAXS simulation to result from interaction with counterions from the medium. 


\section{Introduction}

Anthropogenic activities including nuclear weapon production and testing, disintegration of satellites equipped with nuclear power sources in the atmosphere, or industrial accidents have released substantial amounts of actinides in the environment. ${ }^{1-4}$ The element plutonium, which was thought to be highly immobile regarding its very low solubility in aquatic systems and high sorption ability onto minerals, has been proved to move on the scale of kilometers. ${ }^{1,2,5}$ Both pseudo- and intrinsic plutonium colloids have been reported to be potentially involved in the environmental migration of actinides thus strengthening the need for a better description and characterization of their structure. ${ }^{2}{ }^{3}$ Pseudo-colloids usually refer to natural colloids on which Pu has been incorporated or adsorbed whereas intrinsic ones relies on the ability of $\mathrm{Pu}$ to precipitate and form its own colloid. Research progress on $\mathrm{Pu}(\mathrm{IV})$ colloids is however particularly challenging because of the complex chemistry of the element Pu and the high radioactivity of all of its isotopes requiring careful handling. ${ }^{6}$ A rigorous characterization for these species is particularly important since the apparent solubility of the colloids strongly depends on the size of the nanoparticles composing the suspensions. ${ }^{3,} 7,8$ Furthermore, solubility and interactions with the environment (dissolution, redox interactions, adsorption, complexation, etc.) may be significantly impacted by the nanoparticle speciation and the chemical nature of their surface. $^{9-11}$

Tetravalent $\mathrm{Pu}$ exhibits an intricate behavior in aqueous solutions due to its tendency to disproportionation and hydrolysis., ${ }^{6,12-14}$ The formation of very stable $\mathrm{Pu}(\mathrm{IV})$ colloidal suspensions (referred to as intrinsic colloids but also polymers or eigen colloids in the literature) may result through olation or oxolation mechanisms even at relatively high nitric acid concentration $(0.5 \mathrm{M}) .{ }^{12,}{ }^{15-17}$ The preparation of stable suspensions of intrinsic $\mathrm{Pu}(\mathrm{IV})$ colloids can be managed through several methods including the precipitation from $\mathrm{Pu}(\mathrm{IV})$ solutions with alkali and peptization, ${ }^{6,13}$ radiolytic processes with $\mathrm{Pu}$ ions, ${ }^{6,18}$ or the "simple" pouring of nitric $\mathrm{Pu}(\mathrm{IV})$ solutions at room temperature or boiling pure water. ${ }^{6,19-21}$ Recently, an alternative synthesis method using sonochemistry was proposed for the preparation of stable intrinsic $\mathrm{Pu}(\mathrm{IV})$ colloids in pure water free of electrolytes or stabilizing agents. ${ }^{22}$ The proposed formation mechanism involves the ultrasound-assisted dissolution of bulk $\mathrm{PuO}_{2}$ powder into $\mathrm{Pu}(\mathrm{III})$ ions followed by its reoxidation and subsequent hydrolysis. High Resolution Transmission Electron Microscopy (HR-TEM) and X-ray Absorption Spectroscopy (XAS) techniques allowed to describe these stable colloidal suspensions as quasi-spherical and monodispersed $\mathrm{PuO}_{2}$-like nanoparticles of ca. $7.1 \mathrm{~nm}$ in diameter in comparison to the ca. $2.9 \mathrm{~nm}$ reported for "conventional" hydrolytic colloids. ${ }^{22}$ These previous results described both sonochemical and hydrolytic Pu colloids as core-shell nanoparticles composed of $\mathrm{PuO}_{2}$ cores covered by hydrolyzed Pu(IV) moiety shells.

Despite the growing interest given to intrinsic $\mathrm{Pu}(\mathrm{IV})$ colloids in the literature, the physicochemical properties of these species are still poorly understood. It appears therefore 
essential to better characterize their structural properties which partly impact their stability and fate in aqueous environmental conditions. The available characterization methods reported so far (LIBD, ALS, XAS, HR-TEM, etc.) agree with the description of $\mathrm{PuO}_{2}$-like nanoparticles or clusters ranging from 1 to several hundred of $\mathrm{nm}$ depending on the synthesis procedure. $6,10,19,20,23$ HR-TEM, which appears as a method of choice for particle size characterization, may nevertheless involve sample alteration during the grid preparation or their measurement (e.g. aggregation, oxidation, modification under the beam, drying in the TEM column, etc.) that can misrepresent the particle size in colloidal suspensions and suffer from a weak statistics in counting single objects (localized measurements). ${ }^{24}$ Alternatively, scattering techniques are very useful to probe directly in the synthesis solution, the nanoparticle size and morphology (i.e., shape or form) and the nature of the interactions between the particles without any specific sample preparation. This nonintrusive technique providing in-situ information averaged over large sample volumes and measurements in the native environment appears therefore ideal for Pu colloidal systems. $24-26$

To our knowledge, only two papers report the use of neutron or X-ray based scattering techniques (SANS and SAXS, respectively) for intrinsic Pu(IV) colloid or nanoparticle characterizations. ${ }^{20,27}$ Thiyagarajan et al. prepared polymeric $\mathrm{Pu}(\mathrm{IV})$ colloidal suspensions by diluting and $70 \mathrm{~h}$ aging of a $0.09 \mathrm{M} \mathrm{Pu}(\mathrm{IV})$ solution in $\mathrm{H}_{2} \mathrm{O}-\mathrm{HNO}_{3}(\mathrm{pH}=1.3)$ followed by $8 \mathrm{~h}$ heating at $95^{\circ} \mathrm{C}^{20}$ The related SANS experiments in absolute scale revealed a highly elongated assembly of $\mathrm{Pu}$ oxides, polydispersed in length of more than $190 \mathrm{~nm}$ with a diameter of ca. $4.7 \mathrm{~nm}$ (not observed under electron microscopy). Alternatively, Romanchuk et al. precipitated $\mathrm{Pu}$ oxide nanoparticles by neutralization of $\mathrm{Pu}(\mathrm{III}), \mathrm{Pu}(\mathrm{IV}), \mathrm{Pu}(\mathrm{V})$ or $\mathrm{Pu}(\mathrm{VI})$ ions with ammonia solutions. ${ }^{27}$ HR-TEM investigations pointed at the formation of much more uniform particles (diameter of ca. $2.5 \mathrm{~nm}$ ) whereas SAXS data acquired on these solid samples, in relative intensity scale, did not provide the accurate determination of the particle size or structure but highlighted a high size polydispersity. SAXS technique has been recently developed on the MARS beamline of synchrotron SOLEIL (France) which is dedicated to the study of radioactive samples. The high photon flux and high energy combined with the low spectral width of the incident beam allow a better signal definition on a wider $Q$ range in comparison to classical X-ray sources. ${ }^{25}$ This analytical bench allows characterizing Pu colloidal suspensions by combining SAXS and XAS measurements. In this work, the simultaneous multi-scale SAXS/XAS characterization of intrinsic Pu(IV) colloids (local structure, size, morphology and aggregation properties) has been carried using colloidal suspensions prepared by hydrolysis of ionic $\mathrm{Pu}(\mathrm{IV})$ in the presence of nitrate ions and sonolysis of $\mathrm{PuO}_{2}$ powder in pure water.

\section{Experimental}


Plutonium solutions were prepared in a glove box at the Atalante Facility, Marcoule (France). Mother solution of $\mathrm{Pu}(\mathrm{IV})$ stabilized in ca. $2.5 \mathrm{M} \mathrm{HNO}_{3}$ was obtained by standard purification onto anion exchange resin. ${ }^{28}$ The isotopic composition (wt.\%) was $96.9 \%{ }^{239} \mathrm{Pu}, 2.99 \%{ }^{240} \mathrm{Pu}$, $0.06 \%{ }^{241} \mathrm{Pu} ; 0.02 \%{ }^{238} \mathrm{Pu}$.

A hydrolytic colloidal suspension was obtained by diluting a small volume of $\mathrm{Pu}(\mathrm{IV})$ mother solution with Milli-Q water $\left(18.2 \mathrm{M} \Omega . \mathrm{cm}\right.$ at $\left.25^{\circ} \mathrm{C}\right)$ under vigorous stirring $(\mathrm{pH} 2-3)$. A green emerald and limpid solution was formed after few seconds and a steady state was reached after about fifteen days (no more evolution of the UV-Vis spectra is observed after this period). The resulting solution had a composition of ca. $10 \mathrm{mM} \mathrm{Pu}$ and $42 \mathrm{mM} \mathrm{HNO}_{3}$. This solution was then diluted in $42 \mathrm{mM} \mathrm{HNO}_{3}$ solution or Milli-Q water to reach the following plutonium concentrations: $5 \mathrm{mM} ; 1 \mathrm{mM} ; 0.5 \mathrm{mM}$ or $0.1 \mathrm{mM}$.

The sonolytic (or sonochemical) colloidal suspension ( $\mathrm{pH}=\mathrm{ca}$. 3) was synthesized by $20 \mathrm{kHz}$ sonication of $\mathrm{PuO}_{2}$ nanopowder under $\mathrm{Ar} /(10 \%) \mathrm{CO}$ atmosphere $\left(0.34 \mathrm{~W} . \mathrm{mL}^{-1}, 20-21^{\circ} \mathrm{C}\right) . \mathrm{PuO}_{2}$ nanopowder was previously prepared by adding $30 \mathrm{wt} . \%$ ammonia solution into stirred $\mathrm{Pu}(\mathrm{IV})$ acid solutions in the presence of polyethylene glycol (PEG, $\mathrm{M}=3000,2.5 \mathrm{wt}$ \%). ${ }^{29}$ The precipitates were then heated in air with a constant rate of $10^{\circ} \mathrm{C} \mathrm{min}^{-1}$ up to $485^{\circ} \mathrm{C}$ during 2 $\mathrm{h}$ (with a plateau at $120^{\circ} \mathrm{C}$ during $1 \mathrm{~h}$ ). The synthesis of a stable colloidal suspension was carried out by sonicating ca. $180 \mathrm{mg}$ of $\mathrm{PuO}_{2}$ nanopowder dispersed into $50 \mathrm{~mL}$ of pure water during $27 \mathrm{~h}$. The obtained mixture was centrifuged ( $9000 \mathrm{rpm}, 2 \times 15 \mathrm{~min}$ ) in order to remove the powder that did not react and isolate the stable colloidal suspension. The detailed study and thorough characterization of these species can be found elsewhere. ${ }^{22} \mathrm{An}$ aliquot of the obtained green colloidal suspension was diluted 10 times in Milli- $Q$ water. The sonolytic colloid concentration was determined by alpha spectroscopy (Genie 2000, Canberra, France) after deposition and calcination of a $50 \mu \mathrm{L}$ solution aliquot on an inox disc.

According to previous investigations and the literature, these samples are composed of suspended oxide nanoparticles supporting the colloidal nature of the aqueous systems under study (IUPAC definition). 2, 10, 13, 22, 23, 30, 31 The above-described synthesis procedures and dilutions allowed to observe stable colloidal suspensions of plutonium, i.e. without sedimentation during the duration of the study. It is important to emphasize that the sonolytic colloid is nevertheless less stable than the hydrolytic colloid. Flocculation occurs for the former after several months whereas the latter is stable for several years (samples prepared 5 years ago are still within the form of an optically clear suspension, without sedimentation).

\section{UV-vis absorption spectrophotometry}

UV-vis absorption spectra of the as-prepared intrinsic colloidal suspensions were recorded using a UV3600 Shimadzu spectrophotometer between $350 \mathrm{~nm}$ and $1000 \mathrm{~nm}$ with $1 \mathrm{~cm}$ 
plastic cuvettes. The measurement cell was deported inside the glove box thanks to optical fibers connected to the apparatus from outside the enclosure.

\section{Measurement by synchrotron radiation}

Small Angle X-ray Scattering (SAXS) and X-ray Absorption Spectroscopy (XAS) experiments were performed on the Multi Analyses on Radioactive Samples (MARS) beamline at the synchrotron SOLEIL (Saint-Aubin, France). ${ }^{32}$ The storage ring was operating in top-up mode at an electron current of $500 \mathrm{~mA}, 2.5 \mathrm{GeV}$. The optics were composed of two long platinumcoated mirrors inserted before and after a double-crystal monochromator (DCM) for beam focusing and specific harmonics rejection. Beam energy calibration was performed at the Yttrium edge corresponding to $17.038 \mathrm{keV}$. The focused beam size on sample was $300 \mu \mathrm{m} \mathrm{x}$ $400 \mu \mathrm{m}$. A specific cell was used for radioactive samples and was composed of Teflon sample holders containing three slots of $250 \mu \mathrm{L}$ closed by two layers of Kapton ${ }^{\circledR}$ films (polyimide) on each side.

\section{Small Angle X-ray Scattering (SAXS)}

SAXS experiments were carried out with an X-ray energy of $17 \mathrm{keV}$ corresponding to an average wavelength of $0.7294 \AA^{-1}$, and a sample to detector distance of $785.70 \mathrm{~mm}$. This configuration allows covering a Q-range between about $0.1 \mathrm{~nm}^{-1}$ and $18.8 \mathrm{~nm}^{-1}$. A He gas filled reservoir holding the centered photodiode beam stop was placed between the sample holder and the 2D detector (MAR345) in order to reduce the air scattering. Fig. S1 (ESI) provides a picture of the analytical bench developed for the combined SAXS/XAS measurements. Sample transmissions were recorded during $10 \mathrm{~s}$ using photodiodes and scattering diagrams were recorded during $5 \mathrm{~s}$ per sample. Isotropic 2D scattering data were azimuthally averaged to obtain the scattering intensity $I(Q)$ using Fit2D software. Sample scattering intensity was then normalized by the acquisition time, transmission and thickness, and multiplied by a normalization constant determined with the help of the scattering intensity of polyethylene (PE) at $Q=0.36 \mathrm{~nm}^{-1}$ that corresponds to $4.9 \mathrm{~cm}^{-1}$. The absolute intensity scattered by colloids was finally obtained by subtracting the empty cell, solvent and background contributions. Data were simulated using the SasView 4.2.0 software (http://www.sasview. Org) ${ }^{33}$ especially for core-shell, lamella and disk form factors.

\section{Pu LIII-edge X-ray Absorption Spectroscopy (XAS)}

Experimental spectra were recorded in fluorescence mode using a Ge multi-element detector at the $\mathrm{Pu} \mathrm{L}_{\| I}$-edge (see Fig. S1, ESI). The samples were oriented at $45^{\circ}$ with respect to the incident beam. The incident energy was calibrated using a metallic $\mathrm{Zr}$ foil (K-edge defined at $17.988 \mathrm{keV}$ ). Pu ionization energy was defined at the maximum of the white line and corresponds to $18.068 \mathrm{keV}$. Each XAS spectrum corresponds to the average of 3 to 7 preprocessing scans obtained after ca. 60 to $90 \mathrm{~min}$ of analysis. XANES spectra were extracted by subtraction of the pre-edge background absorption and normalization of the edge to an absorbance value of 1 . EXAFS data were analyzed with Athena and Arthemis software from 
the IFEFFIT package. ${ }^{34}$ Fits were obtained using a Keiser-Bessel window in the $2.5 \AA^{-1}<k<15$ $\AA^{-1}$ range of the $k^{3}$-weighted spectra (FEFF8.4 program). ${ }^{35}$

To avoid misinterpretations, the data treatment was standardized. A second fitting approach was compared by treating the first Pu-O shell separately to avoid artefact generation from long $\mathrm{k}$ range in agreement with a previous report. ${ }^{36}$ Briefly, the normalization, background subtraction and Fourier Transform (FT) of the Pu-O shell were performed on the normalized absorption spectra truncated at $\mathrm{k}=10 \AA^{-1}$ to avoid interferences with the Pu-Pu coordination sphere. A back FT was then carried out in the $\mathrm{R}-\varphi=1.1-2.5 \AA$ range and a single Pu-O path was used to fit the back-Fourier transform. The Debye-Waller factor (DWF, $\sigma^{2}$ ) was considered as a floating parameter while the coordination number (CN) and the Pu-O distance parameters were fixed to 8 and $2.34 \AA$, respectively, in agreement with the ideal $\mathrm{PuO}_{2}$ fluorite structure. The Pu-Pu shell was treated on the FT of the $\mathrm{k}^{3}$-weighted EXAFS in the $2.5-15 \AA^{-1}$ range where the DWF, $\mathrm{R}_{\mathrm{Pu}-\mathrm{Pu}}$ and $\mathrm{CN}$ were considered as floating parameters.

Experimental spectra of bulk $\mathrm{PuO}_{2}$ powder obtained by thermal conversion of $\mathrm{Pu}(\mathrm{IV})$ oxalate at $650^{\circ} \mathrm{C}$ were used as a reference. In addition, theoretical EXAFS spectrum of Pu38 cluster published by Soderholm et al. ${ }^{12}$ was generated for comparison by preserving all of the atomic positions with the exception of the 54 chlorine atoms at the particle surface that were substituted by $24 \mu^{1}-\mathrm{OH}$ group, $24 \mu_{2}-\mathrm{OH}$ and $6 \mathrm{H}_{2} \mathrm{O}$ at $2.25 \AA, 2.32 \AA$ and $2.50 \AA$, respectively. The DWF parameters were fixed according to available EXAFS measurements on actinide hexanuclear clusters $\left(0.003 \mathrm{~A}^{2}\right.$ for $\mu_{1}-\mathrm{OH}$ and $\mu_{3}-\mathrm{O}$ bonds; $0.005 \mathrm{~A}^{2}$ for $\mu_{4}-\mathrm{O}, \mathrm{H}_{2} \mathrm{O}$ molecules and Pu-Pu interactions). ${ }^{37,} 38$ The EXAFS oscillations calculated for the $38 \mathrm{Pu}$ atoms are then averaged to produce the spectrum.

\section{Results and discussion}

\section{Synthesis and absorption spectroscopy}

Hydrolytic and sonolytic Pu(IV) intrinsic colloids, respectively, were prepared by dilution of a $\mathrm{Pu}(\mathrm{IV})$ solution stabilized in nitric acid with pure water and by extended sonication $(20 \mathrm{kHz}$ ultrasound, $\left.\mathrm{Ar} /(10 \%) \mathrm{CO}, 20 \pm 1^{\circ} \mathrm{C}\right)$ of bulk $\mathrm{PuO}_{2}$ powder dispersed in pure water (see details in experimental section). ${ }^{22}$ Whatever the synthesis procedure, stable (i.e., without sedimentation), limpid and green colloidal suspensions were obtained. UV-vis absorption spectra of both hydrolytic and sonolytic colloidal suspensions are provided in Fig. 1 . The hydrolytic colloid spectrum displays four peaks located at $\lambda=578 \mathrm{~nm}, 615 \mathrm{~nm}, 688 \mathrm{~nm}$ and $735 \mathrm{~nm}$ characteristic of intrinsic Pu(IV) colloids. ${ }^{6,22,31,39,40} \mathrm{~A}$ high absorption region observed for $\lambda<550 \mathrm{~nm}$ can be attributed to Mie scattering in agreement with the presence of suspended nanoparticles in this sample. These features agree with the sonolytic colloid spectrum with however a lower intensity for the absorption bands which evidence a lower nanoparticle concentration for this sample. A sharp peak located at $830 \mathrm{~nm}$ is only observed for the hydrolytic colloid spectrum indicating the presence of $\mathrm{Pu}(\mathrm{VI})$ ion traces in the solution. ${ }^{22}$ This species results from Pu(IV) disproportionation (Eq. 1) and chemical oxidation 
of $\mathrm{Pu}(\mathrm{V})$ by $\mathrm{Pu}(\mathrm{IV})$ in weakly acid solution (Eq. 2), and corresponds to a $\mathrm{Pu}$ concentration lower than $0.32 \mathrm{mM}\left(<3.2 \%\right.$, with $\left.\varepsilon_{830}=555 \mathrm{M}^{-1} \cdot \mathrm{cm}^{-1}\right)$. ${ }^{6,}{ }^{41}$ Both, equation Eq. 1 (slow step) and Eq. 2 (rapid equilibrium) can be summarized by equation Eq. 3. Note that $\mathrm{Pu}(\mathrm{IV})$ disproportionation depends on $\mathrm{H}^{+}$concentration at the fourth order and is therefore not favored at high acidity. ${ }^{6}$ The absence of $\mathrm{Pu}(\mathrm{III})$ in these conditions may be explained by the catalytic oxidation of $\mathrm{Pu}(\mathrm{III})$ according to equations Eq. 4-5, but also by the low molar extinction coefficient of $\mathrm{Pu}(\mathrm{III})$.

$$
\begin{aligned}
& 2 \mathrm{Pu}^{4+}+2 \mathrm{H}_{2} \mathrm{O} \rightleftarrows \mathrm{Pu}^{3+}+\mathrm{PuO}_{2}^{+}+4 \mathrm{H}^{+} \\
& \mathrm{Pu}^{4+}+\mathrm{PuO}_{2}^{+} \rightleftarrows \mathrm{Pu}^{3+}+\mathrm{PuO}_{2}^{2+} \\
& 3 \mathrm{Pu}^{4+}+2 \mathrm{H}_{2} \mathrm{O} \rightleftarrows 2 \mathrm{Pu}^{3+}+\mathrm{PuO}_{2}^{2+}+4 \mathrm{H}^{+} \\
& 2 \mathrm{Pu}^{3+}+3 \mathrm{H}^{+}+\mathrm{NO}_{3}^{-} \rightarrow 2 \mathrm{Pu}^{4+}+\mathrm{HNO}_{2}+\mathrm{H}_{2} \mathrm{O} \\
& \mathrm{Pu}^{3+}+\mathrm{HNO}_{2}+\mathrm{H}^{+} \rightarrow \mathrm{Pu}^{4+}+\mathrm{NO}+\mathrm{H}_{2} \mathrm{O}
\end{aligned}
$$

Dilution of the as-prepared hydrolytic colloidal suspensions in $42 \mathrm{mM} \mathrm{HNO}_{3}$ or pure water preserves the optically clear solutions (i.e., without sedimentation) and does not modify the position of the absorption signals (the intensity decrease is related to the lower concentration of the colloids in the suspensions) as evidenced by the spectra provided in supplementary materials (see Fig. S2, S3 and S4, ESI). The list of the mother and dilute samples (and related composition) is gathered in Table 1. By assuming a total Pu(IV) conversion into Pu(IV) colloid, the molar absorption coefficient of the hydrolytic colloid suspension at $\lambda=615 \mathrm{~nm}$ is approximated to be about $13 \mathrm{M}^{-1} \cdot \mathrm{cm}^{-1}$. This value suffers from reliability due to the absence of comparison data in the literature attributed to uncertainties and a lack of reproducibility concerning nanoparticle sizes and concentrations. ${ }^{39,40}$

Fig. 1 UV-Vis absorption spectra of $10 \mathrm{mM}$ hydrolytic (blue line) and $0.8 \mathrm{mM}$ sonolytic (red line) intrinsic colloids. Characteristic bands are indicated in the inset with dotted lines $(\lambda=578,615,688$ and $735 \mathrm{~nm}$ ) where the intensity of the sonolytic colloid is multiplied by 7 and the black star $\left({ }^{*}\right)$ indicates an artefact due to the optical fibers. $\mathrm{Pu}(\mathrm{VI})$ absorption band located at $\lambda=830 \mathrm{~nm}$ is indicated in orange. Despite this high absorption band, the concentration of $\mathrm{Pu}(\mathrm{VI})$ in the solution is less than $3.2 \%$ of the total $\mathrm{Pu}$ concentration. 


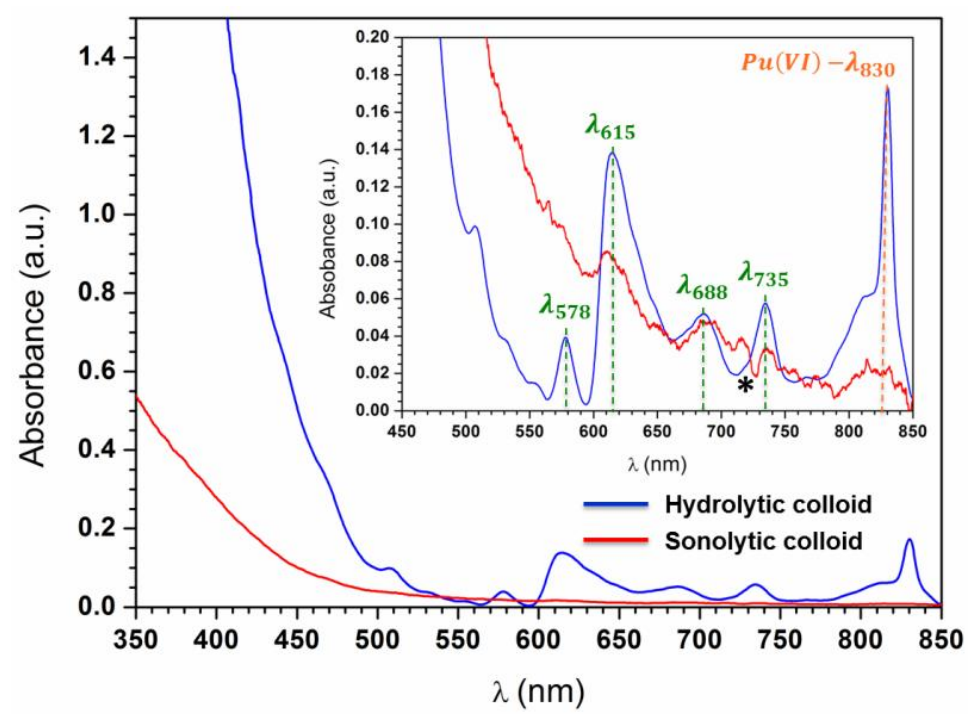

Table 1 Hydrolytic $(\mathrm{HC})$ and sonolytic $(\mathrm{SC})$ colloidal suspension compositions, theoretical volume fraction $\left(\varphi_{\mathrm{th}}\right)$ calculated for a total $\mathrm{Pu}(\mathrm{IV})$ conversion into colloid and based on $\mathrm{PuO}_{2}$ molar volume, and core volume fraction $\left(\varphi_{\text {core }}\right)$ determined from $I_{0}$ value of the core-shell fitting model. All of the as prepared solutions were stable, optically clear without sedimentation during the whole experiments.

\begin{tabular}{clll}
\hline Sample name & {$[\mathrm{Pu}] /\left[\mathrm{HNO}_{3}\right]$} & $\boldsymbol{\varphi}_{\text {th }}(\%)$ & $\boldsymbol{\varphi}_{\text {core }}(\%)$ \\
\hline Hydrolytic colloid $(\mathrm{HC})$ & & & \\
$\mathrm{HC}-10-\mathrm{HNO}_{3}$ & $10 \mathrm{mM} / 42 \mathrm{mM}$ & 0.024 & 0.017 \\
$\mathrm{HC}-5-\mathrm{HNO}_{3}$ & $5 \mathrm{mM} / 42 \mathrm{mM}$ & 0.012 & 0.008 \\
$\mathrm{HC}-1-\mathrm{HNO}_{3}$ & $1 \mathrm{mM} / 42 \mathrm{mM}$ & 0.0024 & - \\
$\mathrm{HC}-0.5-\mathrm{HNO}_{3}$ & $0.5 \mathrm{mM} / 42 \mathrm{mM}$ & 0.0012 & 0.0003 \\
$\mathrm{HC}-0.1-\mathrm{HNO}_{3}$ & $0.1 \mathrm{mM} / 42 \mathrm{mM}$ & 0.00024 & - \\
$\mathrm{HC}-5-\mathrm{H}_{2} \mathrm{O}$ & $5 \mathrm{mM} / 21 \mathrm{mM}$ & 0.012 & 0.008 \\
$\mathrm{HC}-1-\mathrm{H}_{2} \mathrm{O}$ & $1 \mathrm{mM} / 11 \mathrm{mM}$ & 0.0024 & 0.0011 \\
Sonolytic colloid (SC) & & & \\
SC-0.8- $\mathrm{H}_{2} \mathrm{O}$ & $0.8 \mathrm{mM} / 0 \mathrm{mM}$ & - & - \\
SC-0.08- $\mathrm{H}_{2} \mathrm{O}$ & $0.08 \mathrm{mM} / 0 \mathrm{mM}$ & - & - \\
\hline * calculated from core-shell simulation &
\end{tabular}

SAXS analysis: characterization of the particle size, morphology and aggregation properties The normalized SAXS diagrams measured for the mother solutions of both hydrolytic and sonolytic colloids (noted $\mathrm{HC}-10-\mathrm{HNO}_{3}$ and $\mathrm{SC}-0.8-\mathrm{H}_{2} \mathrm{O}$ respectively, in Table 1 ) are given in absolute units in Fig. 2. A different scattering pattern underlining strong differences in particle size and morphology for both kind of samples is clearly observed. To our knowledge, this is the first time that SAXS diagrams in absolute unit are reported for stable $\mathrm{Pu}$ colloidal suspensions on such a wide Q-range. This configuration is of high potential for data fitting and initial intensity $\left(\mathrm{I}_{0}\right)$ analysis. The slope displayed for the hydrolytic colloid is $Q^{0}$ for low wave vectors and tends towards $\mathrm{Q}^{-4}$ at higher wave vectors which is characteristic of a sharp interface, typical for three-dimensional objects and compact particles. ${ }^{25,42,43}$ The slope of the scattering curve of the sonolytic colloid exhibits a closer $Q^{-2}$ at low wave vectors which ends with a $Q^{-4}$ at larger wave vectors. These features are often attributed to twodimensional elongated objects such as infinitely thin disks or lamellas. ${ }^{25}$ 
Fig. 2 SAXS diagrams of $10 \mathrm{mM}$ hydrolytic (blue line) and $0.8 \mathrm{mM}$ sonolytic (red line) intrinsic Pu(IV) colloids. Black lines indicate the slope power laws. The oscillation at $Q=4 \mathrm{~nm}^{-1}$ is an artefact attributed to the scattering of the kapton windows of the sample holder.

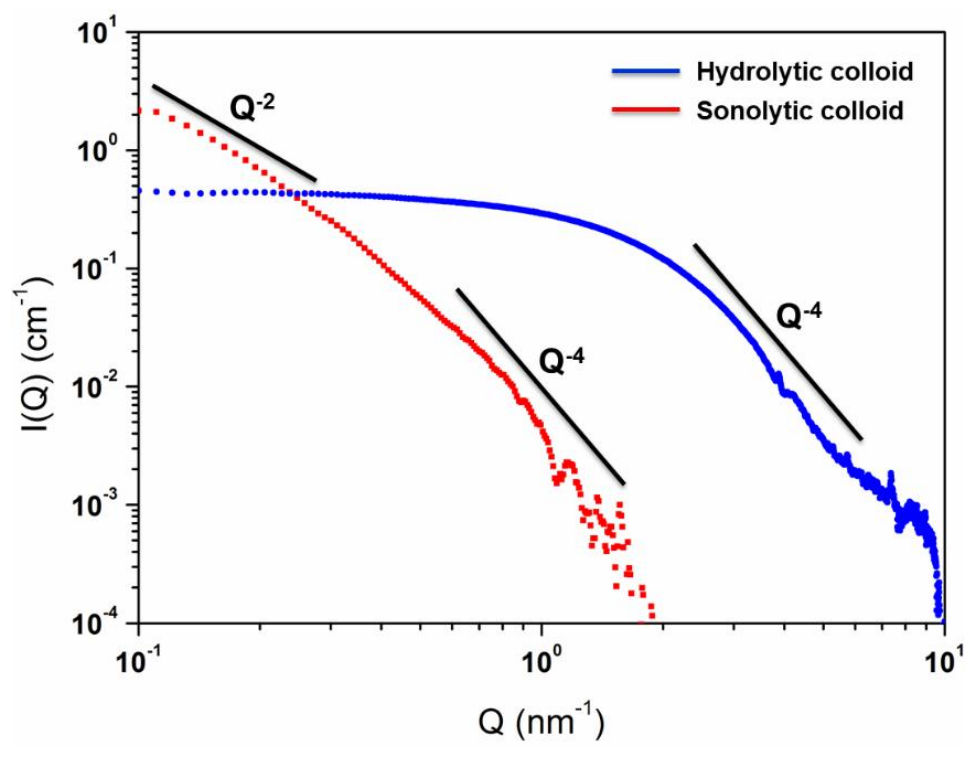

In the present work, the large wave vector reached for the stable colloidal suspensions allow determining the particle sizes with a good approximation using simple fitting models. SAXS scattering diagrams are generally described with the following equation (Eq. 6) where $I_{0}$ is the initial intensity for $\mathrm{Q}$ approaching 0 value (very small angles), $P(Q)$ is the form factor which provides information about the particle size and morphology, and $S(Q)$ is the structure factor which provides information about the interactions between the particles. This last function equal unity for dilute solutions.

$$
I(Q)=I_{0} P(Q) S(Q)
$$

Table 2 Molar volume $\left(V_{m}\right)$, X-ray scattering length density $\left(\rho_{c}\right)$ and electron contrast $\left(\Delta \rho^{2}\right)$ used for SAXS diagram simulation calculations. Values for $\mathrm{PuO}_{2}$ are based on the dense oxide density $(\mathrm{d}=11.5)$.

\begin{tabular}{lcccc}
\hline & $\begin{array}{c}\mathrm{V}_{\mathrm{m}} \\
\left(10^{-23} \mathrm{~cm}^{3}\right)\end{array}$ & $\begin{array}{c}\rho_{\mathrm{c}} \\
\left(10^{10} \mathrm{~cm}^{-2}\right)\end{array}$ & $\begin{array}{c}\Delta \rho^{2} \\
\left(10^{23} \mathrm{~cm}^{-4}\right)\end{array}$ \\
\hline $\mathrm{PuO}_{2}$ & 3.99 & 77.78 & $\mathrm{PuO}_{2} / \mathrm{H}_{2} \mathrm{O}$ & 4.672 \\
$\mathrm{H}_{2} \mathrm{O}$ & 2.99 & 9.43 & & \\
\hline
\end{tabular}

Table 2 summarizes the molar volume $V_{m}$, the scattering length density $\rho_{c}$ and the contrast $\Delta \rho^{2}$ used for the calculations. The high electron density of plutonium offers a very high contrast with the bulk solution (the scattering length density of $42 \mathrm{mM}$ nitric acid solution does not differ significantly from pure water: $9.43410^{10} \mathrm{~cm}^{-2}$ against $9.42810^{10} \mathrm{~cm}^{-2}$, respectively). SAXS diagrams obtained for the sonolytic colloid do not reach the $Q^{0}$ plateau at low wave vector. Moreover, the Porod law at high $Q$ range cannot be observed due to the low colloidal concentration. These two assertions explain the difficulty to determine $S(Q)$ 
contribution in the Eq. 6. However, due to the low colloid concentration, it was assumed that $S(Q)=1$. The fit results are provided in Table 3 and the corresponding simulated curves are compared to experimental ones in Fig. 3a for infinitely thin lamella and disk models. Fit models result in a limit size value of $3.77(50) \mathrm{nm}$ in thickness in the lamella model and about $5 \quad 5.29(50) \mathrm{nm}$ in thickness and $15.98 \mathrm{~nm}$ as a minimum radius in the case of the disk model (see Table 3). A better reproducibility is observed with the disk model when comparing the sonolytic colloid $\left(\mathrm{SC}-0.8-\mathrm{H}_{2} \mathrm{O}\right)$ and its dilute sample $\left(\mathrm{SC}-0.08-\mathrm{H}_{2} \mathrm{O}: \mathrm{L}=6.13 \mathrm{~nm}\right.$ and $\mathrm{R}_{\mathrm{D}}>15.81 \mathrm{~nm}$; see Fig. S5, ESI).

Table 3 Simulation results of SAXS diagrams obtained with SasView software: $I_{0}$ is the intensity for $Q \rightarrow 0, R_{G}$ the gyration radius, $R$ the radius of the sphere, $R_{\text {core }}$ the radius of the core, $T_{\text {shell }}$ the thickness of the shell, $\rho_{\text {shell }}$ the scattering length density of the shell, $L$ the thickness of the lamellar or disk and $R_{D}$ the radius of the disk. The standard deviation of the variable parameters estimated using SasView is indicated in brackets.

\begin{tabular}{|c|c|c|c|c|c|c|c|c|c|c|}
\hline \multicolumn{2}{|c|}{ Sample information } & \multicolumn{9}{|c|}{ Model } \\
\hline \multirow[b]{2}{*}{ Name } & \multirow[b]{2}{*}{$\begin{array}{c}\mathrm{I}_{0} \\
\left(\mathrm{~cm}^{-1}\right)\end{array}$} & \multicolumn{2}{|c|}{ Guinier } & Sphere & \multicolumn{3}{|c|}{ Core-Shell } & Lamella & \multicolumn{2}{|c|}{ Disk } \\
\hline & & $\begin{array}{c}\mathrm{R}_{\mathrm{G}} \\
(\mathrm{nm})\end{array}$ & $\begin{array}{c}\mathrm{R} \\
(\mathrm{nm})\end{array}$ & $\begin{array}{c}\mathrm{R} \\
(\mathrm{nm})\end{array}$ & $\begin{array}{l}R_{\text {core }} \\
(\mathrm{nm})\end{array}$ & $\begin{array}{l}T_{\text {shell }} \\
(\mathrm{nm})\end{array}$ & $\begin{array}{c}\rho_{\text {shell }} \\
\left(10^{10} \mathrm{~cm}^{-2}\right)\end{array}$ & $\begin{array}{c}\mathrm{L} \\
(\mathrm{nm})\end{array}$ & $\begin{array}{c}\mathrm{L} \\
(\mathrm{nm})\end{array}$ & $\begin{array}{c}\mathrm{R}_{\mathrm{D}} \\
(\mathrm{nm})\end{array}$ \\
\hline \multicolumn{11}{|c|}{ Hydrolytic colloid (HC) } \\
\hline $\mathrm{HC}-10-\mathrm{HNO}_{3}$ & $0.42(2)$ & $1.04(5)$ & $1.34(7)$ & $1.30(10)$ & $0.93(10)$ & $1.45(20)$ & $10.64(50)$ & - & - & - \\
\hline $\mathrm{HC}-5-\mathrm{HNO}_{3}$ & $0.20(2)$ & $1.01(5)$ & $1.304(70)$ & $1.25(10)$ & $0.95(10)$ & $1.25(20)$ & $10.93(50)$ & - & - & - \\
\hline $\mathrm{HC}-0.5-\mathrm{HNO}_{3}$ & $0.013(5)$ & $1.01(5)$ & $1.304(70)$ & $1.23(10)$ & $1.23(10)$ & $-*$ & $13.51(50)$ & - & - & - \\
\hline $\mathrm{HC}-5-\mathrm{H}_{2} \mathrm{O}$ & $0.20(8)$ & $1.01(5)$ & $1.304(70)$ & $1.25(10)$ & $0.90(10)$ & $1.03(20)$ & $11.91(50)$ & - & - & - \\
\hline $\mathrm{HC}-1-\mathrm{H}_{2} \mathrm{O}$ & $0.036(20)$ & $1.01(2)$ & $1.30(3)$ & $1.27(10)$ & $1.08(10)$ & $1.56(20)$ & $10.36(50)$ & - & - & - \\
\hline \multicolumn{11}{|c|}{ Sonolytic colloid (SC) } \\
\hline $\mathrm{SC}-0.8-\mathrm{H}_{2} \mathrm{O}$ & $2.2(5)$ & - & - & - & - & - & - & $3.77(50)$ & $5.29(50)$ & $>15.98(10)$ \\
\hline $\mathrm{SC}-0.08-\mathrm{H}_{2} \mathrm{O}$ & $0.06(1)$ & - & - & - & - & - & - & $-* *$ & $6.13(60)$ & $>15.81(10)$ \\
\hline
\end{tabular}

Fig. 3 Fit models applied to: a) $0.8 \mathrm{mM}$ sonolytic colloid $\left(\mathrm{SC}-0.8-\mathrm{H}_{2} \mathrm{O}\right)$ diagram: lamella model (blue line) and disk model (red line), and b) $10 \mathrm{mM}$ hydrolytic colloid ( $\left.\mathrm{HC}-10-\mathrm{HNO}_{3}\right)$ SAXS diagram: Guinier model (black line), sphere form factor (red line) and spherical core-shell form factor (green line).
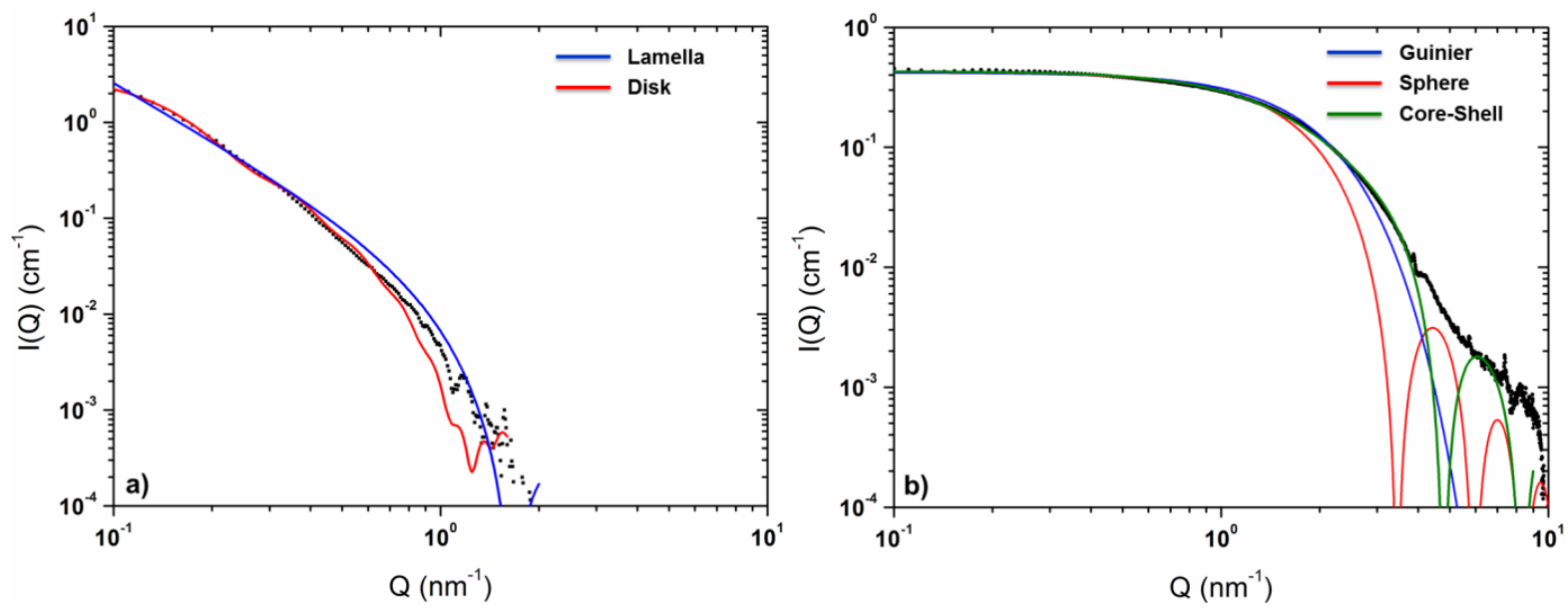
To evaluate a possible $S(Q)$ factor for the hydrolytic colloid, the mother solution of the $10 \mathrm{mM}$ hydrolytic colloid $\left(\mathrm{HC}-10-\mathrm{HNO}_{3}\right)$ was diluted in $42 \mathrm{mM} \mathrm{HNO}$ solution or pure water (see Table 1). The corresponding SAXS diagrams, normalized by their theoretical volume fraction $\left(\varphi_{\text {th }}\right)$, are plotted in Fig. S6, ESI $\left(\mathrm{HC}-0.1-\mathrm{HNO}_{3}\right.$ sample diagram was not usable due to the too low particle concentration of the suspension that did not scatter enough). All the curves are overlapping which indicates the absence of significant interactions between the nanoparticles composing the various Pu suspensions in the concentration range studied (10 $\mathrm{mM}-0.5 \mathrm{mM})$. In addition, it is very important to emphasize that the similarity between the scattering diagrams of the various hydrolytic colloids diluted in $\mathrm{HNO}_{3}$ or $\mathrm{H}_{2} \mathrm{O}$ (Fig. S6, ESI) also indicates a poor ionic strength effect on the particle size and morphology (i.e., shape). These observations allow to consider $S(Q)$ parameter equaled to 1 for all of the hydrolytic colloid samples in the equation (Eq. 6).

Hydrolytic colloid diagrams were then fitted using three different models (see ESI for model descriptions): ${ }^{42,44,45}$ (i) Guinier model, (ii) monodisperse sphere form factor model, and (iii) spherical core-shell model (Fig. 3b). In the first two models, the initial intensity is defined with the equation described hereinafter (Eq. 7) with $\varphi_{\mathrm{P}}$, the volume fraction of the particle, $V_{p}$, its volume and $\Delta \rho^{2}$, the electronic contrast with the solvent. ${ }^{44}$

$$
I_{0}=\varphi_{P} V_{P} \Delta \rho^{2}
$$

(i) Guinier analysis, which gives a first approach of the particle radius of gyration $R_{G}$ by fitting the $Q^{0}$ plateau and the inflexion of the SAXS curve, fails however by fitting the data for $Q>3 \mathrm{~nm}^{-1}$. A radius of gyration of ca. $1 \mathrm{~nm}$ is found for all of the hydrolytic colloid samples (see Table 3). The radius of gyration is known to be greatly affected by particle shape, aggregation, improper solvent and background subtraction and polydispersity. ${ }^{42}$ Considering spherical and filled particles, the radius of the particles can be deduced with the following equation (Eq. 8) where, $R$ is the radius of the sphere.

$$
R_{G}=R \sqrt{(3 / 5)}
$$

The determined radius of $1.3 \mathrm{~nm}$ (see Table 3 ) is in good agreement with the literature data discussing the nanoparticle size composing intrinsic $\mathrm{Pu}$ (IV) colloidal suspensions. ${ }^{10,19,22,23}$ (ii) Best fits obtained with the monodisperse sphere form factor model is also consistent with a sphere radius $\mathrm{R}$ of about $1.3 \mathrm{~nm}$ agreeing with the Guinier model (red line, Fig. $\mathbf{3 b}$ and Table 3). Gaussian and Lognormal polydispersities were tentatively applied to improve the model, particularly for data $Q>1.5 \mathrm{~nm}^{-1}$, however without significant improvement (see Fig. S5, ESI). Extending this model to the four other hydrolytic colloid samples leads to the same particle size strengthening the absence of influence of the media on the size and morphology (i.e., the shape) of the hydrolytic colloid mother solution $\left(\mathrm{HC}-10-\mathrm{HNO}_{3}\right)$ and its dilute samples. 
(iii) The spherical core-shell model consists in fitting a nanoparticle spherical core radius $R_{\text {core, }}$ a shell thickness $T_{\text {shell, }}$ the scattering length density of the shell $\rho_{\text {shell }}$ and the volume fraction of the colloid. For simplicity, the colloid core was assumed to have an ideal $\mathrm{PuO}_{2}$ fluorite-type Fm-3m oxide structure with a scattering length density defined in Table 2 . The fits performed on the five hydrolytic colloid scattering diagrams were found to converge to similar values with $0.90<\mathrm{R}_{\text {core }}<1.08 \mathrm{~nm}$ and $1.03<\mathrm{T}_{\text {shell }}<1.45 \mathrm{~nm}$ with an average $\rho_{\text {shell }}=$ $10.9610^{10} \mathrm{~cm}^{-2}$. The $\mathrm{HC}-0.5-\mathrm{HNO}_{3}$ sample is different from the others because only a core radius could be fit. This is likely due to the poor statistics data at high $Q$ range for this highly diluted sample. Furthermore, the volume fraction of the core extracted from the fitted $I_{0}$ values of each sample is found to be slightly lower but consistent with the theoretical volume fraction given in Table 1. Such observations underline the good reproducibility of the fitting procedure and strengthen the relevance of this core-shell model.

These results raise the question of the origin and nature of the shell that surrounds the $\mathrm{PuO}_{2}$ nanoparticle cores in nitric acid solutions. The scattering length density values obtained with the simulation are slightly higher than those of pure water indicating an excess of electron density surrounding the nanoparticle surface. Such excess can be induced by the presence of $\mathrm{Pu}-\mathrm{OH}$ surface functions, $\mu 3$-oxo bonds, nanoparticle curvature, surface roughness, etc. ${ }^{22,46 \text {, }}$

${ }^{47}$ Nevertheless, these parameters only account for the rising electronic density but do not explain the thickness and composition of this shell in the presence of $\mathrm{H}^{+}$and $\mathrm{NO}_{3}^{-}$ions. According to the core-shell model, this shell corresponds to several atomic layers (ca. 1.32 $\mathrm{nm}$ ). Abdel-Fattah et al. have previously performed zeta potential measurements on $\mathrm{PuO}_{2}$ particles of around $100 \mathrm{~nm}$ size. ${ }^{48}$ Their results showed that $\mathrm{PuO}_{2}$ particles are positively charged for $\mathrm{pH}$ value lower than the isoelectric point (8.6) and correspond to a zeta potential of ca. $60 \mathrm{mV}$ for $\mathrm{pH}<3$.

This positive charge is the surface charge of the Stern-Helmholtz layer which corresponds to the stationary hydration layer and the attached counter-ion layer. The whole is surrounded by the diffuse layer (or Gouy-Chapman layer) which contains mobile co-ions and counter ions. Both layers (Gouy-Chapman and Stern), in addition to other possible functions existing at the particle surface (i.e., hydroxo and oxo groups, adsorbed water, etc.), may contribute to the scattering length density of the shell in the current model. Yet, it remains difficult to distinguish between them. By considering only nitrate $\mathrm{NO}_{3}{ }^{-}$as a counter-ion with an ionic radius of ca. $200 \mathrm{pm},{ }^{49}$ a shell composed of ca. 3.3 compact layers of $\mathrm{NO}_{3}{ }^{-}$can be deduced which corresponds to a local concentration of ca. 3.6 M (Fig. 4). An attempt to improve this fitting model was made using a scattering length density gradient profile (Fig. S5, ESI) but this model remains less satisfactory than the core-shell model. Alternative models such as a multilayer model (i.e. onion-like form factor) could be used to improve the fitting method with higher statistics at high $\mathrm{Q}$ range which might be obtained with more concentrated 
solutions. Considering this first dataset, the core-shell model gives nevertheless a consistent explanation for intrinsic Pu(IV) hydrolytic colloid morphology (shape).

Fig. 4 X-Ray scattering length density profile of intrinsic Pu(IV) hydrolytic colloid and representation of spherical colloid composed of a $\mathrm{PuO}_{2}$ core surrounded by shell containing nitrate ion in bulk solution drawn from SasView simulation results.

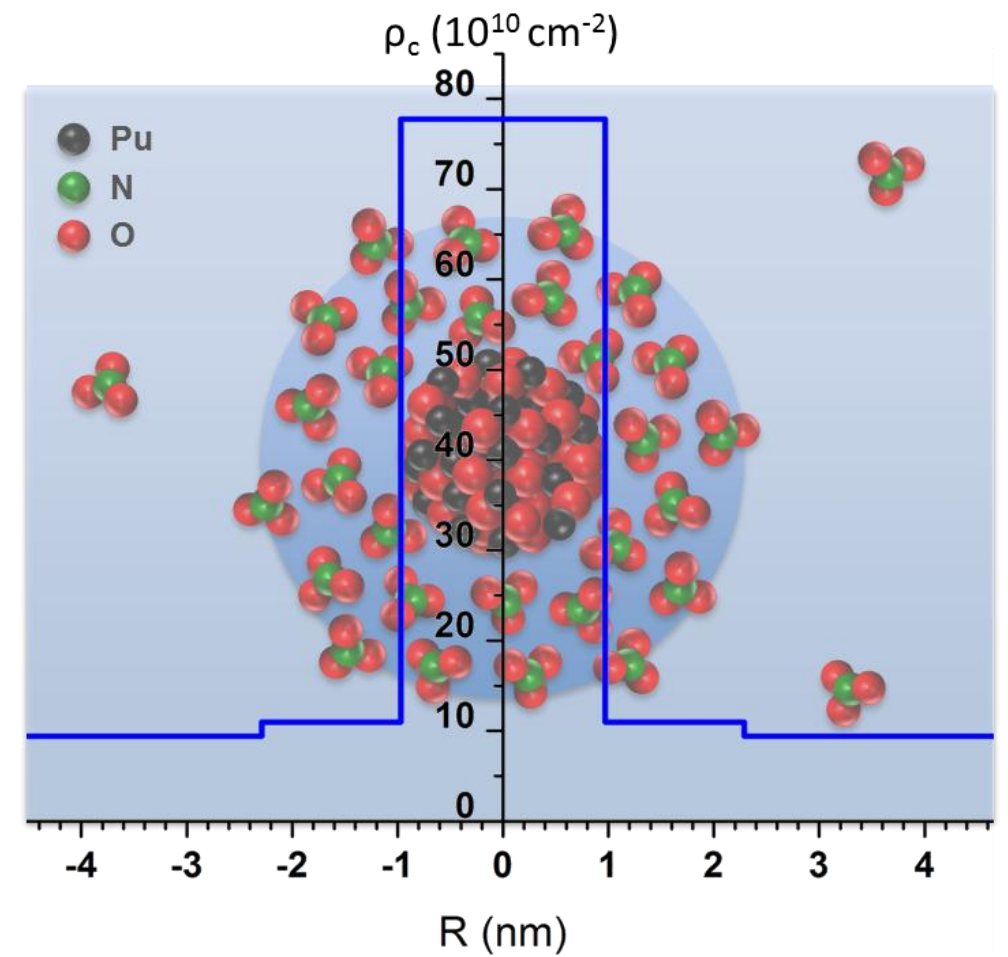

The size of the core (around 2.0(3) $\mathrm{nm}$ in diameter) determined for the hydrolytic colloids agrees with previous HR-TEM observations performed on such nanoparticles. ${ }^{10,19,22,23}$ By contrast, previous HR-TEM investigations carried out on intrinsic sonolytic colloids revealed the presence of quasi-spherical particles with an average diameter of about $7.1 \mathrm{~nm}^{22}$ (see pictures in Fig. S7, ESI). The particle size discrepancies noticed when comparing previous microscopy results with the current SAXS values could arise from three different factors: (i) the HR-TEM sample preparation involving a drying step, ${ }^{24}$ (ii) the different $\mathrm{PuO}_{2}$ precursor used during sonolysis in the two studies (nanostructured $\mathrm{PuO}_{2}$ composed of ca. $10 \mathrm{~nm}$ sintered particles vs. a nanopowder composed of ca. $5 \mathrm{~nm}$ particles in the current study $)^{22}$ and (iii) a possible aggregation or flocculation phenomenon occurring with the nanoparticles in the colloidal suspension, even after dilution in water. This last hypothesis observation also agrees with the lower stability observed for the sonolytic colloid (several months) in comparison to the hydrolytic colloid (> several years).

Furthermore, this aggregation phenomenon was already mentioned by Thiyagarajan et al. who performed SANS characterization on intrinsic $\mathrm{Pu}(\mathrm{IV})$ colloidal suspensions. ${ }^{20}$ These stable colloids, prepared by the heating method, were found to be composed of aggregated and ellipsoidal nanoparticles of ca. $4.7 \mathrm{~nm}$ in diameter and more than $190 \mathrm{~nm}$ long. ${ }^{6,20} \mathrm{~A} \mathrm{Q}^{-2}$ 
slope has also been observed by Romanchuk et al. on SAXS diagrams obtained from precipitated $\mathrm{PuO}_{2}$ nanoparticles of ca. $2.5 \mathrm{~nm}$ diameter in agreement with their HR-TEM data. ${ }^{27}$ In this case, the precise shape of the precipitated $\mathrm{PuO}_{2}$ nanoparticles was not determined with SAXS. Some possible particle agglomeration was proposed to explain the $Q^{-}$

$5{ }^{2}$ decay observed in the scattering diagrams. ${ }^{27}$ Whatever the study, determining the longest dimension of such elongated particles is technically difficult because of the low Q-range accessibility (limited sample-detector distance). In any case, the observation of these elongated or agglomerated nanoparticles raises the question of the charge and surface nature of these particles.

SAXS results point out that comparable sonolytic and hydrolytic intrinsic $\mathrm{Pu}(\mathrm{IV})$ colloids may display a different pattern that corresponds to elongated slab and spherical core-shell, respectively. This difference may be attributed to the synthesis method itself and the related formation mechanism of the nanoparticles. While the hydrolytic intrinsic $\mathrm{Pu}(\mathrm{IV})$ colloid is formed by hydrolysis of $\mathrm{Pu}^{4+}$ ions (in competition with disproportionation), the sonolytic intrinsic Pu(IV) colloid has been proposed to be formed in a two-step process: (i) reductive dissolution of the bulk $\mathrm{PuO}_{2}$ nanopowder accumulating $\mathrm{Pu}$ (III) in solution, followed by (ii) reoxidation and hydrolysis of $\mathrm{Pu}(\mathrm{IV}) .{ }^{22}$ In addition, the contrasted particle shape may also arise from the difference in the solvent nature during synthesis: pure water (salt free) vs. nitrate solution. In the case of the hydrolytic colloid, the presence of the electrolyte induces the formation of a counter-ion layer (coordinated or not) at the particle surface that may prevent agglomeration. Further investigations, especially on the nanoparticle surface charge need to be performed to elucidate this phenomenon.

XAS analysis: local structure and nanoscale effects (The whole XAS part has been changed, updated and improved)

Pu $\mathrm{L}_{\text {III }}$ edge X-ray Absorption Near-Edge Structure (XANES) spectra acquired for a selection of hydrolytic and sonolytic colloid samples $\left(\mathrm{HC}-10-\mathrm{HNO}_{3} ; \mathrm{HC}-5-\mathrm{HNO}_{3} ; \mathrm{HC}-5-\mathrm{H}_{2} \mathrm{O}\right.$ and SC-0.8$\mathrm{H}_{2} \mathrm{O}$ ) are presented in Fig. 5a and Fig. S8 (ESI). Pu LIII XANES allows investigating the unoccupied $\mathrm{Pu} 6 \mathrm{~d}$ states and is a good tool for probing the oxidation state. The synchrotron measurements of the colloidal suspensions performed over at least 4 hours did not show any significant variation as emphasized with the spectra provided in Fig. S9, ESI. This important point combined to the absence of sedimentation and to the long term stability of the colloidal suspensions (checked with absorption spectroscopy) validates our result and demonstrates the absence of significant redox transformations or beam damage during our study. Good spectra similarities in terms of shape, position and intensities can indeed be observed between the studied colloidal samples but also with bulk $\mathrm{PuO}_{2}$ powder used for comparison in Fig. 5a (derivatives are given in Fig. S10, ESI). This observation also agrees with XANES spectra of $\mathrm{Pu}(\mathrm{IV})$ intrinsic colloid from the literature. ${ }^{15,22,50,51}$ The energy position of the white line (WL) evidences a similar electronic structure $(<1 \mathrm{eV}$ difference) for 
all of the samples: $18068.4 \mathrm{eV}$ for $\mathrm{SC}-0.8-\mathrm{H}_{2} \mathrm{O}, 18068.0 \mathrm{eV}$ for $\mathrm{PuO}_{2}$ reference and 18067.4 $\mathrm{eV}$ for all of the hydrolytic colloids $\left(\mathrm{HC}-10-\mathrm{HNO}_{3} ; \mathrm{HC}-5-\mathrm{HNO}_{3}\right.$ and $\left.\mathrm{HC}-5-\mathrm{H}_{2} \mathrm{O}\right)$.

Fig. 5 a) Pu $\mathrm{L}_{3}$ XANES and corresponding b) $\mathrm{k}^{3}$-weighted experimental EXAFS spectra acquired on a selection of hydrolytic and sonolytic colloids $\left(\mathrm{HC}-10-\mathrm{HNO}_{3} ; \mathrm{HC}-5-\mathrm{HNO}_{3} ; \mathrm{HC}-5-\mathrm{H}_{2} \mathrm{O}\right.$ and $\left.\mathrm{SC}-0.8-\mathrm{H}_{2} \mathrm{O}\right) . \mathrm{PuO}_{2}$ bulk powder is provided as a reference. The legend given in a) can be used for both figures.
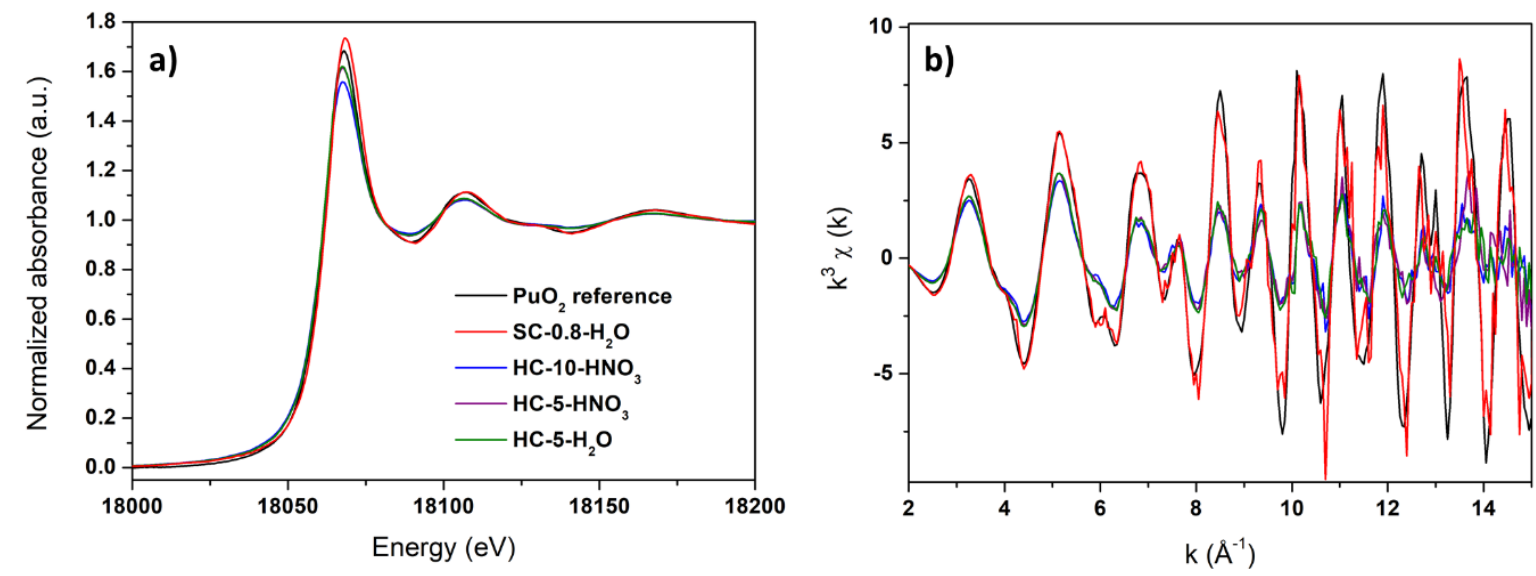

In comparison to molecular $\mathrm{Pu}(\mathrm{IV})^{47,} 49$ plutonium intrinsic colloids show a similar position with a lower amplitude combined to a wider and asymmetrical WL as recently evidenced by Vitova et al. ${ }^{50}$ In this study, the authors combined XANES and computations to demonstrate that intrinsic $\mathrm{Pu}(\mathrm{IV})$ colloids exhibit band-like $6 \mathrm{~d}$ states similar to bulk $\mathrm{PuO}_{2}$ contrasting with the narrower $6 \mathrm{~d}$ states expected in molecular $\mathrm{Pu}(\mathrm{IV})$ species. The similar XANES spectral shape observed for bulk $\mathrm{PuO}_{2}$ and $\mathrm{Pu}$ intrinsic colloids was then attributed to a splitting of the $6 \mathrm{~d}$ states crystal field. ${ }^{50}$ These observations support the (+IV) oxidation states for the samples investigated in the current study. Slight energy shifts might be attributed to the potential presence of covalent $\mathrm{Pu}-\mathrm{O}$ bonds expected for $\mathrm{Pu}(\mathrm{V})$ or $\mathrm{Pu}(\mathrm{VI})$ species (trans di-oxo bonds) and the observation of an "yl" shoulder at ca. $18086 \mathrm{eV}$, which feature is not observed for these samples, or at least too low to be noticed (see Fig. S11, ESI). ${ }^{50,52}$ Nanoparticle surface moieties $\left(\mathrm{OH}, \mathrm{H}_{2} \mathrm{O}\right.$, etc.) or structural defects such as $\mathrm{O}$ vacancies could also participate in XANES spectra variations. Slight WL variations have also been attributed to different aging and/or ripening processes for intrinsic $\mathrm{Pu}(\mathrm{IV})$ colloids. ${ }^{53}$ The very small differences observed in Fig. 5a are not significant enough to be interpreted; the use of high resolution XANES techniques such as HERFD (High Energy Resolution Fluorescence Detection) as well as $M$ edge measurements might provide further information. ${ }^{50,54-56}$ Nevertheless, the used experimental conditions and the thorough inspection of our spectra at this stage suggest the very strong predominance of (+IV) oxidation state for plutonium in the colloid samples (the exclusive presence of $\mathrm{Pu}(\mathrm{IV})$ cannot be affirmed from sole $\mathrm{Pu} \mathrm{L}_{\mathrm{III}}$ edge XANES spectra). 
Fig. $\mathbf{5 b}$ provides the experimental $\mathbf{k}^{3}$-weighted EXAFS functions that can be decomposed into low frequency oscillations in the $2-10 \AA^{-1}$ range and high frequency oscillations from 10 to $16 \AA^{-1}$. The overall shape of the spectra is similar for all of the samples. Nevertheless, the hydrolytic colloid samples distinguish from the sonolytic colloid with lower amplitude oscillations in both frequency ranges. The corresponding Fourier transforms (FT) obtained in the $2.5 \AA^{-1}<k<15 \AA^{-1}$ range gathered in Fig. 6 provide a pseudo-radial distribution function describing the coordination sphere of the absorbing Pu atoms (uncorrected for phase shift). These spectra show two main peaks at $\mathrm{R}-\varphi=$ ca. 1.84 and $3.68 \AA$ in agreement with the $k^{3}$ weighted FT spectra of $\mathrm{PuO}_{2}$ used as a reference, but also with previous reports dealing with intrinsic $\mathrm{Pu}(\mathrm{IV})$ colloid and $\mathrm{PuO}_{2}$ samples. ${ }^{22,51,57-60}$ This observation indicates that Pu intrinsic colloids exhibit some similarities with the structure of $\mathrm{PuO}_{2}$ which crystallizes in the face centered cubic system. The position of the two peaks in bulk $\mathrm{PuO}_{2}$ originates from the coordination of $\mathrm{Pu}(\mathrm{IV})$ with $\mathrm{O}$ and $\mathrm{Pu}$ atoms at ca. $2.33 \AA$ and $3.81 \AA$, respectively. ${ }^{61}$

In comparison to $\mathrm{PuO}_{2}$, two distinctive features can be observed for both hydrolytic and sonolytic colloid samples in Fig. 6 . They indeed show (i) reduced oscillation amplitude for both coordination shells, and (ii) a strong asymmetry and distortion of the Pu-O coordination sphere. Both effects are found significantly strengthened for the hydrolytic colloid samples in comparison to the sonolytic colloid which spectra appears intermediate between the hydrolytic ones and the $\mathrm{PuO}_{2}$ reference. This observation shows a trend which agrees with the determined particle sizes probed by SAXS in the first part of the manuscript. It was previously suggested that the EXAFS amplitude reduction results from a strong local disorder in the bulk $\mathrm{Pu}$ atoms (decrease of crystallinity and increase of the DWF) and/or by a nanoparticle surface effect attributed to the increasing proportion of plutonium atoms standing at the particle surface in comparison to the bulk when decreasing in size (S/V atomic ratio). ${ }^{15,22,36,51,53}$ The more specific distortion of the $\mathrm{Pu}-\mathrm{O}$ coordination sphere has been suggested to result from a splitting of the $\mathrm{Pu}-\mathrm{O}$ distances in the $\mathrm{Pu}$ oxide local structure. Several hypotheses have been discussed to explain the nature of these bonds including the presence of $\mathrm{Pu}-\mathrm{OH}, \mathrm{Pu}-\mathrm{O}$ and $\mathrm{Pu}-\mathrm{H}_{2} \mathrm{O}$ distances, $\mathrm{O}$ defects or also the presence of short $\mathrm{Pu}=\mathrm{O}$ oxo bonds found in $\mathrm{Pu}(\mathrm{V})$ or $\mathrm{Pu}(\mathrm{VI})$ moieties. ${ }^{15,50,53,58,59,62}$ The two above hypotheses (bulk disorder and enhanced surface atom contribution) result in similar effects on the EXAFS spectra and are hence difficult to distinguish.

Fig. 6 Fourier transforms (FT) of the $\mathrm{k}^{3}$-weighted $2.5-15 \AA^{-1}$ interval for a selection of hydrolytic and sonolytic $\mathrm{Pu}(\mathrm{IV})$ intrinsic colloids $\left(\mathrm{HC}-10-\mathrm{HNO}_{3} ; \mathrm{HC}-5-\mathrm{HNO}_{3} ; \mathrm{HC}-5-\mathrm{H}_{2} \mathrm{O}\right.$ and $\left.\mathrm{SC}-0.8-\mathrm{H}_{2} \mathrm{O}\right)$. Additional FT of bulk $\mathrm{PuO}_{2}$ and simulated Pu38 cluster are provided as references. The small peak standing at $\mathrm{R}-\varphi=1.6 \AA$ results from the $\mu_{0}$ spline function subtraction when applied to $k_{\max }>11 \AA^{-1}$. This treatment generates or suppress very low frequency noise without any physical meaning for $\mathrm{Pu}-\mathrm{O}$ distances. 


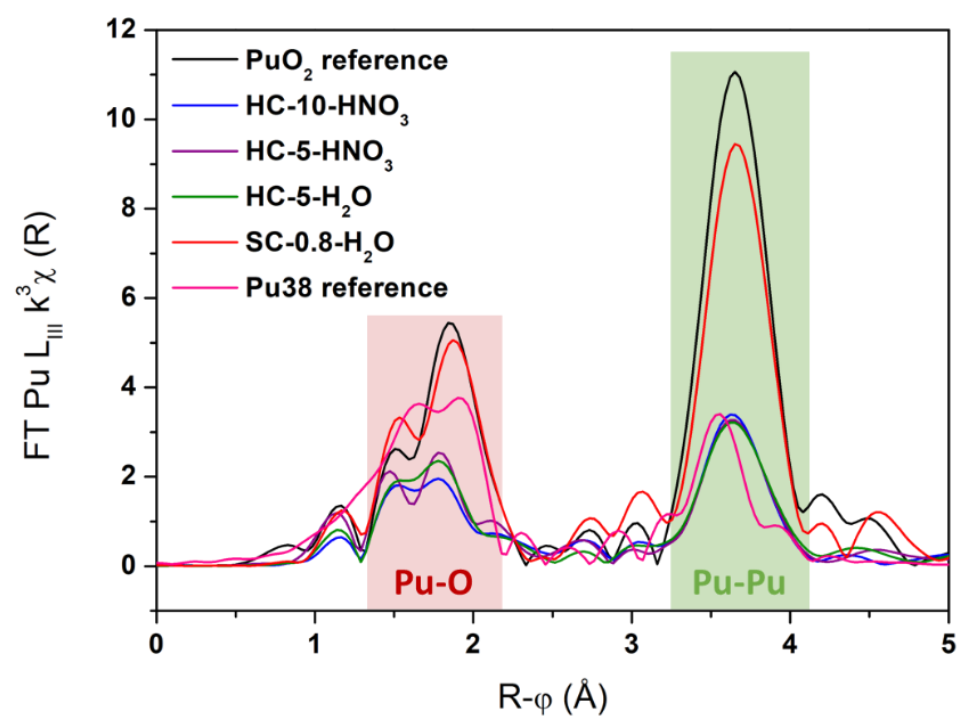

5 The aforementioned spectra variations are obviously related to a nanoscale effect and we emphasize that EXAFS interpretation becomes therefore challenging. ${ }^{63}$ Particularly, these atomic scale variations constrain the data interpretation and analyses to a careful step by step process in which the outcome of any fit model must be considered with caution and self-criticism. Moreover the double-electron excitation signal observed in the Pu LIII edge is likely to complicate the data treatment. ${ }^{64}$ Performing fits of quality for such samples which exhibit $\mathrm{PuO}_{2}$-like structures has been proved to be tricky and generally result from a compromise between the number of subshells used to reproduce the $\mathrm{Pu}-\mathrm{O}$ coordination sphere and their corresponding Debye-Waller factor (DWF). Such assertions explain and reinforce our strategy consisting in the consideration of comparable samples exhibiting different specific sizes and morphologies. In a previous study, we reproduced with a good agreement the experimental EXAFS spectra of sonolytic and hydrolytic colloids using a constrained three O-shell model with $\mathrm{Pu}-\mathrm{O}_{\text {short }}$ (for $\mu_{1}-\mathrm{Pu}-\mathrm{OH}$ or $\left.\mu_{3}-\mathrm{Pu}-\mathrm{O}\right), \mathrm{Pu}-\mathrm{O}_{\text {medium }}$ for $\left(\mu_{4^{-}}\right.$ $\mathrm{O}$ from $\mathrm{PuO}_{2}$ ideal structure) and $\mathrm{Pu}-\mathrm{O}_{\text {long }}$ (for surface-adsorbed $\mathrm{H}_{2} \mathrm{O}$ molecules) distances. A good correlation was highlighted between the size of the colloids and the $\mathrm{Pu}-\mathrm{O}_{\text {short }}$ coordination numbers suggested to hypothetical $\mathrm{Pu}-\mathrm{OH}$ and $\mu_{3}-\mathrm{Pu}-\mathrm{O}$ moieties possibly standing at the surface of the nanoparticles.

We recently proposed an alternative fitting approach that allowed us to compare a selection of nanoscale $\mathrm{AnO}_{2}$ oxide powders ( $\mathrm{An}=\mathrm{Pu}$ and Th). ${ }^{36}$ Similarly, the FT EXAFS spectra acquired for these samples were found to agree with $\mathrm{AnO}_{2}$ EXAFS spectra with differences in shell peak intensities and the observation of a distortion and asymmetry of the first An-O shell gradually increasing with the shrinking nanoparticles (or crystallites) composing the samples. We used a single An-O scattering path to fit a Fourier filtered An-O sphere and determine the corresponding DWF, which is the only floating parameter in this approach but allows 
measuring the local disorder around the absorbing atom. The results revealed a strong dependency between the as-obtained DWF parameters and the size of the nanoparticles (and/or crystallites) composing the $\mathrm{AnO}_{2}$ powder samples. Of particular interest was the similar behaviour evidenced between analogous $\mathrm{ThO}_{2}$ and $\mathrm{PuO}_{2}$ samples for which the DWF was found to consistently increase as a function of the crystallite size. Such trend allowed to rely the distortion of the An-O shell to a nanoparticle effect and exclude the contribution of high-valence $\mathrm{Pu}$ atoms in the measured $\mathrm{PuO}_{2}$ samples since Th oxidation state is only (+IV) in these conditions. This last approach was considered in the current work and compared to fits obtained on a larger $k$ range in order to discuss the results on regard of SAXS measurements and corresponding geometrical models. The extracted structural parameters, using the $\mathrm{PuO}_{2}$-based fitting procedure described above and in the experimental section, are gathered in Table 4 (FT best fits and scattering paths provided in Fig. S12 and S13, ESI). Furthermore, considering the small size of the particles (ca. $1 \mathrm{~nm}$ radius), we found appropriate to compare our spectra with the crystallographic model of the Pu38 cluster published by Soderholm et al. (see description in experimental section and FT in Fig. 6). ${ }^{12}$

Table 4 EXAFS structural parameters calculated from $k^{3}$-weighted EXAFS spectra (CN: coordination number; R: interatomic distance, DWF: Debye-Waller factor). For the first $\mathrm{Pu}-\mathrm{O}$ coordination sphere parameters, $\mathrm{R}_{\mathrm{Pu}-\mathrm{O}}=$ $2.33 \AA$ and $\mathrm{CN}_{\mathrm{Pu}-\mathrm{O}}=8$, were fixed in accordance with the crystalline fcc $\mathrm{PuO}_{2}$ structure. $\Delta \mathrm{E}_{0}=4.8 \mathrm{eV}, \mathrm{S}_{0}^{2}=0.9$. The standard deviations measured using IFEFFIT software are given in parentheses. ${ }^{34} \mathrm{PuO}_{2}$ obtained by thermal conversion of $\mathrm{Pu}(\mathrm{IV})$ oxalate at $650^{\circ} \mathrm{C}$ was used as a reference. Pu38 reference data were obtained from the crystallographic model published by Soderholm et al. ${ }^{12}$

\begin{tabular}{|c|c|c|c|c|c|}
\hline Samples & $\begin{array}{c}\text { DWF }_{\text {Pu-o }}{ }^{*} \\
\left(10^{-3} \AA^{2}\right) \\
k=2.5-10 \AA^{-1}\end{array}$ & $\begin{array}{c}\mathrm{DWF}_{\mathrm{Pu}-\mathrm{O}}{ }^{* *} \\
\left(10^{-3} \AA^{2}\right) \\
k=2.5-15 \AA^{-1}\end{array}$ & $\mathrm{CN}_{\mathrm{Pu}-\mathrm{Pu}}{ }^{* *}$ & $\begin{array}{c}\mathrm{R}_{\mathrm{Pu}-\mathrm{Pu}}{ }^{* *} \\
(\AA \AA)\end{array}$ & $\begin{array}{c}\text { DWF }_{\text {Pu-Pu }}{ }^{* *} \\
\left(10^{-3} \AA^{2}\right) \\
k=2.5-15 \AA^{-1}\end{array}$ \\
\hline Pu38 reference & \multicolumn{2}{|c|}{$14.9(1.2)$} & $4.4(1.4)$ & $3.80(1)$ & $10.0(1.0)$ \\
\hline $\mathrm{HC}-10-\mathrm{HNO}_{3}$ & $16.7(1.0)$ & $15.2(1.0)$ & $5.1(9)$ & $3.81(1)$ & $5.9(7)$ \\
\hline $\mathrm{HC}-5-\mathrm{HNO}_{3}$ & $14.9(7)$ & $13.5(7)$ & $5.0(1.7)$ & $3.80(1)$ & $5.9(1.4)$ \\
\hline $\mathrm{HC}-5-\mathrm{H}_{2} \mathrm{O}$ & $15.0(8)$ & $13.5(8)$ & $5.7(1.3)$ & $3.80(1)$ & $6.7(8)$ \\
\hline $\mathrm{SC}-0.8-\mathrm{H}_{2} \mathrm{O}$ & $7.8(6)$ & $6.8(1.0)$ & $8.6(1.8)$ & $3.82(1)$ & $3.7(7)$ \\
\hline $\mathrm{PuO}_{2}$ reference & $5.9(1.0)$ & $5.9(9)$ & 10.5 (1.9) & $3.81(1)$ & $3.5(6)$ \\
\hline
\end{tabular}

*Values obtained using a FT acquired on a $2.5-10 \AA^{-1}$ truncated k-range. Fit was obtained with a single Pu-O path on the back FT performed on the as-filtered Pu-O sphere. ${ }^{* *}$ Values obtained on the $2.5-15 \AA^{-1}$ k-range. Fit were obtained with single $\mathrm{Pu}-\mathrm{O}$ and $\mathrm{Pu}-\mathrm{Pu}$ paths.

A progressive increase of the coordination numbers (CN) determined for the Pu-Pu shell can be observed between the different intrinsic colloid samples: the hydrolytic colloids are ranging from 5.0(1.7) to 5.7(1.3) whereas the sonolytic colloid reaches 8.6(1.8) with $\mathrm{Pu}-\mathrm{Pu}$ distances ranging between 3.80 (1) and 3.82(1) $\AA$. These $\mathrm{CN}$ values are framed by the values determined for $\mathrm{PuO}_{2}(\mathrm{CN}=10.5(1.9)$ and $\mathrm{Pu} 38(\mathrm{CN}=4.4(1.4))$ references and confirm the highlighted trend correlating the DWF parameter and the size of the nanoparticle composing the samples. Nevertheless, the DWF parameter determined using this procedure seems to underestimate the Pu-Pu coordination numbers. The theoretical Pu-Pu coordination number calculated from the crystallographic structure of Pu38 cluster is 7.58 with Pu-Pu interatomic 
distance ranging from $3.53 \AA$ to $3.92 \AA$ whereas the fit results in only 4.4 Pu-Pu interactions at $3.80 \AA$. A similar comment can be raised with regard to the value obtained for $\mathrm{PuO}_{2}$ reference which can be assessed slightly lower than the theoretical one $\left(\mathrm{CN}_{\mathrm{Pu}-\mathrm{Pu}}=10.5(1.9)\right.$ instead of 12). ${ }^{6,61}$ This Pu-Pu distance spreading could result from structural distortion in the 5 Pu-O-Pu network as noticed in Pu38 cluster $^{12}$ or suggested by Walther et al. ${ }^{53}$ Also, a nanoparticle surface effect can be suggested as emphasized with nanoscale $\mathrm{PuO}_{2}$ powders, recently. ${ }^{36}$ In both cases, one could expect that the DWF must account for Pu-Pu distances distribution resulting in more accurate $\mathrm{CN}$ obtained from a single scattering path. This approximation becomes wrong here since the $\mathrm{Pu}-\mathrm{Pu}$ distance distribution becomes too large to be absorbed by DWF parameter.

For the Pu-O shell, the determined DWF is the only floating parameter. The difference in the results provided in Table $\mathbf{4}$ for the two considered fit approaches confirms the influence of the spline function subtraction at high k-range. It is indeed found that considering a too high k-range may involve an overestimation of the DWF parameter for the Pu-O shell that can misrepresent the distances distribution and corresponding CN. Nevertheless, a similar trend is observed for both approaches. Considering the 2.5-10 $\AA^{-1} \mathrm{k}$-range, DWF equals $5.910^{-3} \AA^{2}$ for $\mathrm{PuO}_{2}$ reference, increases to $7.810^{-3} \AA^{2}$ for the sonolytic colloid, and reaches a maximum ranging from $14.910^{-3} \AA^{2}$ to $16.710^{-3} \AA^{2}$ for the hydrolytic colloid samples. This rising DWF parameter demonstrates an increasing disorder in the oxygen shell reflected by a splitting of the Pu-O distances which can be, once again, correlated to the nanoparticle shrinking that compose the colloidal samples in agreement with SAXS data. ${ }^{36}$ Using the single O-shell fit results in a DWF of $14.910^{-3} \AA^{2}$ for the small Pu38 model which is close but slightly lower than the one obtained for $\mathrm{HC}-10-\mathrm{HNO}_{3}$ hydrolytic colloid value. Interestingly, this observation is visually accompanied by a strong splitting and distortion of the $\mathrm{Pu}-\mathrm{O}$ shell on the FT provided in Fig. 6. Obviously, this observation cannot be linked to the potential contribution of higher $\mathrm{Pu}$ oxidation states in the structure in agreement with the resolved structure of Pu38. Multiple Pu(IV)-O bonds in the Pu38 crystal structure rather explain the increase of the DWF such as the very short surface $\mu_{3}-\mathrm{O}$ and $\mu_{1}-\mathrm{OH}$ bonds at $2.1 \AA-2.2 \AA$ as 30 well as corner water molecules found at $2.5 \AA$. This indeed indicates that the same type of short surface bonds are present at the colloid surface. Although being in the standard deviation, the absence of significant difference between the determined DWF parameter for Pu38 and hydrolytic $\mathrm{HC}-10-\mathrm{HNO}_{3}$ can also be attributed to differences in surface roughness or thickness. A structural disorder in the core structure might also be proposed but appears less relevant considering previous XRD and HR-TEM results that demonstrated the crystalline nature of these colloid nanoparticles.

Fig. 7 Theoretical variation of the coordination number for the Pu-Pu coordination shell as a function of the radius for a sphere (dotted black line) or disc (dotted red line) model. The red circle plots (o) represent the experimental data (SAXS vs. EXAFS fit) and the blue squares ( $\square$ ) represent the theoretical $\mathrm{CN}$ for the Pu-Pu sphere calculated from the published crystallographic structures. 


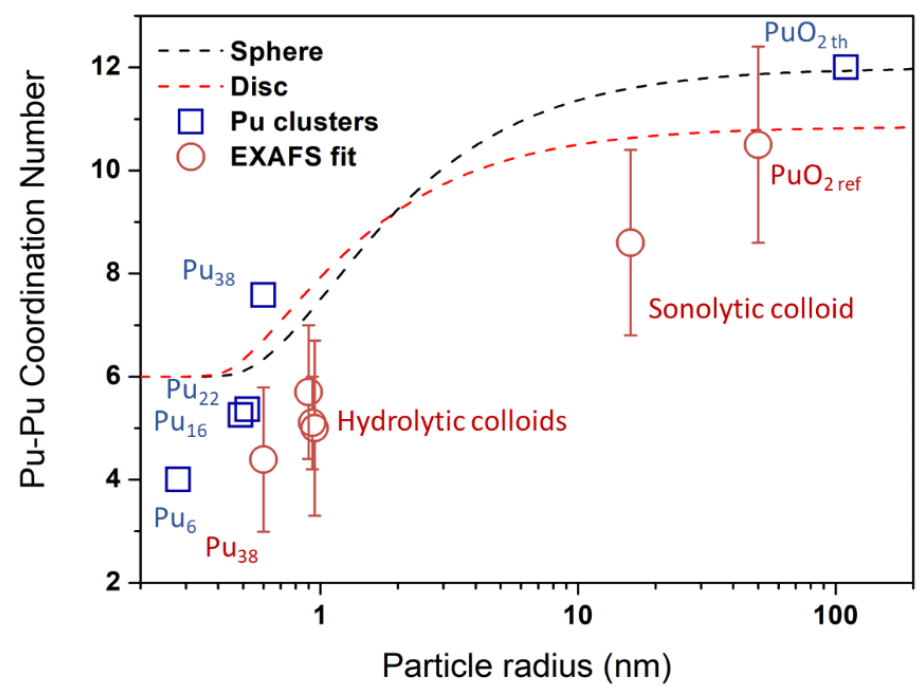

Several studies highlighted the more significant contribution of surface atoms in comparison to bulk when decreasing nanoparticle size (surface to volume ratio). ${ }^{22,36,47}$ This phenomenon is particularly enhanced for nanoparticles measuring less than 10-20 nm in diameter. Geometric calculations allowed us to strengthen this statement by plotting the theoretical averaged Pu-Pu coordination number as a function of the nanoparticle radii (Fig. 7). The nanoparticle radius experimentally determined by SAXS and their Pu-Pu coordination numbers obtained from EXAFS simulations are superimposed on this figure to the geometrical calculations. The theoretical curves were drawn assuming spherical or disc nanoparticles in agreement with used SAXS models. The curves were plotted using a single $\mathrm{Pu}-\mathrm{Pu}$ distance of $0.38 \mathrm{~nm}$ with coordination numbers of $\mathrm{CN}=12$ in the particle bulk and $\mathrm{CN}=$ 6 at the surface (only for the first Pu-Pu layer). A closer look at Pu38 cluster indeed shows that the minimal $\mathrm{CN}$ for Pu-Pu coordination sphere exhibited by surface $\mathrm{Pu}$ atoms is $\mathrm{CN}=6$. Therefore, the determined coordination numbers for nanoparticles exhibiting a spherical shape should not be lower than this value. Interestingly, the experimental points are following a trend similar to the geometrical model with is characterized by a fast increase of the average Pu-Pu CN value at the very beginning of the particle growth (Fig. 7). The elongated disc model used for the sonolytic colloid better explains the low coordination number for the Pu-Pu shell obtained by EXAFS for such big particles in comparison to spherical model. In addition, such elongated colloidal particles could in fact result from spherical particles aggregation (elongated $\mathrm{PuO}_{2}$ nanoparticles are not observed in HR-TEM). However, an offset between both the experimental points and the geometrical model (for both spherical and disc shapes) is observed thus strengthening our concerns about the fit accuracy to reproduce $\mathrm{CN}$ values for the Pu-Pu shell.

Several hypotheses can explain this discrepancy including some particle size polydispersity in addition to some core and surface structural differences. Several studies suggested that clusters made out of 38 actinide atoms are built from the olation and/or oxolation stacking of low nuclearity clusters involving 6, 16 or 22 atoms. Such observation has been highlighted 
for various actinides including uranium, ${ }^{65}$ neptunium ${ }^{66}$ and plutonium. ${ }^{17}$ As showed on Fig. 7, Pu6, Pu16 and Pu22 clusters exhibit low coordination numbers measuring $\mathrm{CN}=4,5.23$, and 5.36, respectively. ${ }^{17,38,67}$ Thus, one might assume that the contribution of such species during the building of intrinsic colloids may contribute in lower coordination numbers for the Pu-Pu sphere. Hence, higher amount of surface defects (e.g., edges, corners, strains, steps...), surface groups (-OH functions, $\mu_{3}$-oxo bonds, adsorbed water molecules...) and under-coordinated surface atoms can be expected for such nanoparticles. ${ }^{15,22,36,46,51,53,63,68}$ These differences may also explain the slight WL XANES differences noted in Fig. 5a between our very similar samples. Several studies indeed demonstrated that XANES spectroscopy (and also EXAFS) may be significantly influenced by the more sensitive local geometry and electronic structure effects provided by nanoscale materials in comparison to bulk samples. $^{27,47,68,69}$

\section{Conclusions}

To our knowledge, we performed the first combined synchrotron-based SAXS and XAS measurements of stable suspensions of intrinsic Pu(IV) colloids. This multi-scale approach allows the quasi-simultaneous probing of the size, morphology (i.e., the shape) and local structure of the nanoparticles composing the suspensions. Using this approach, the rigorous comparison of $\mathrm{Pu}(\mathrm{IV})$ intrinsic colloids prepared by hydrolysis and sonolysis demonstrates that the physico-chemical properties of the intrinsic Pu(IV) colloids are strongly influenced by the preparation method. The fast Pu(IV) hydrolysis in the presence of nitrate anions leads to 2.0(3) $\mathrm{nm}$ spherical nanoparticles characterized by reduced EXAFS spectra with an additional strong splitting of the Pu-O coordination shell. By contrast, sonolytic $\mathrm{Pu}(\mathrm{IV})$ intrinsic colloids prepared in pure water allows the observation of elongated bigger particles of ca. $5.7 \mathrm{~nm}$ thickness and more than $30 \mathrm{~nm}$ large (lamella/disk). The Pu-O shell distortion is less pronounced for this sample and the local structure appears intermediate between hydrolytic colloid and bulk $\mathrm{PuO}_{2}$ powder. Aggregation of nanoparticles in the case of this less stable suspension may explain this specific morphology.

More precisely, the highly debated Pu(IV) intrinsic colloids can be described as core-shell nanoparticles made out of $\mathrm{PuO}_{2}$ core surrounded by a disordered $\mathrm{Pu}-\mathrm{O}$ shell solvated with nitrate counter-ions. The results obtained by both synchrotron SAXS and XAS approaches converge to the conclusion that the observed variations of the local structure for the intrinsic Pu colloids is strongly influenced by the nanoparticle surface when shrinking and highly unlikely results from the contribution of higher Pu oxidation states. The comparison with published data strongly suggests that the interfacial chemistry and nature contribute in the observed variations of the colloid local structure. These observations raise the question of the colloidal suspension stability (counter-ion concentration, colloid surface charge, radiolysis effect, etc.). Future investigations with different salt systems and more concentrated solutions should strengthen this approach and clarify the plutonium colloid 
shell nature. More generally, the multi-scale approach used in this study provides new insights about the local structure, size, morphology (i.e., shape) and interfacial properties of intrinsic Pu(IV) colloids that could help in a better understanding of $\mathrm{Pu}$ migration mechanisms in the environment. 


\section{Graphical abstract}

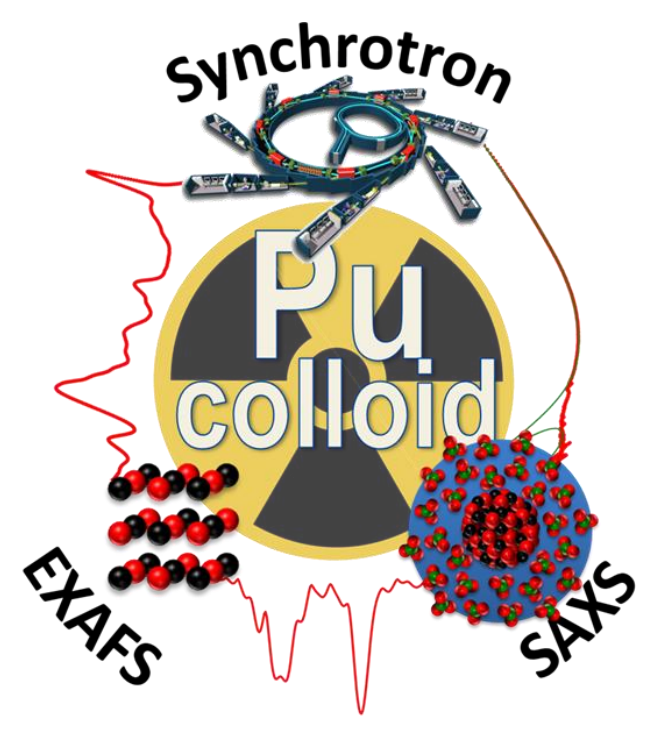

5

\section{Associated Content}

Electronic supplementary information (ESI) available

\section{Author Information}

Corresponding author

*E-mail: matthieu.virot@cea.fr

ORCID ID Matthieu Virot: 0002-6295-2555

\section{Author Contributions}

The manuscript was written through contributions of all authors who gave their approval for submission of the final version of the manuscript.

\section{Notes}

There are no conflicts to declare.

\section{Acknowledgements}

We acknowledge the financial support of RCHIM program and the Cross-Disciplinary Program on bottom up exploratory research program of CEA, the French Alternative Energies and Atomic Energy Commission. The authors gratefully acknowledge Jeremy Causse, Laëtitia Guerin, Myrtille Hunault, Emilie Russello, Bertrand Siboulet and Jackie Vermeulen for fruitful discussions and help in experiments. This work benefited from the use of the SasView application, originally developed under NSF award DMR-0520547. SasView contains code developed with funding from the European Union's Horizon 2020 research and innovation program under the SINE2020 project, grant agreement No 654000. 


\section{References}

1. A. B. Kersting, D. W. Efurd, D. L. Finnegan, D. J. Rokop, D. K. Smith and J. L. Thompson, Migration of plutonium in ground water at the Nevada Test Site, Nature, 1999, 397, 56-59.

5 2. A. B. Kersting, Plutonium Transport in the Environment, Inorganic Chemistry, 2013, 52, 35333546 .

3. C. Walther and M. A. Denecke, Actinide colloids and particles of environmental concern, Chemical Reviews, 2013, 113, 995-1015.

4. Y. Li, L. Xu, P. Bai, G. Rong, D. Zhang, J. Diwu, W. Yan, Z. Chai and S. Wang, Emerging investigator series: significantly enhanced uptake of $\mathrm{Eu}^{3+}$ on a nanoporous zeolitic mineral in the presence of $\mathrm{UO}_{2}{ }^{2+}$ : insights into the impact of cation-cation interaction on the geochemical behavior of lanthanides and actinides, Environ. Sci.: Nano, 2019, 6, 736-746.

5. E. L. Tran, O. Klein-BenDavid, N. Teutsch and N. Weisbrod, Influence of Intrinsic Colloid Formation on Migration of Cerium through Fractured Carbonate Rock, Environmental Science \& Technology, 2015, 49, 13275-13282.

6. D. Clark, S. Hecker, G. Jarvinen and M. Neu, in The Chemistry of the Actinide and Transactinide Elements, eds. L. Morss, N. Edelstein and J. Fuger, Springer Netherlands, 2011, DOI: 10.1007/978-94-007-0211-0_7, ch. 7, pp. 813-1264.

7. T. Kobayashi, T. Sasaki, I. Takagi and H. Moriyama, Effect of solid phase transformation on the solubility product of thorium hydrous oxide at $363 \mathrm{~K}$, Journal of Nuclear Science and Technology, 2016, 53, 1787-1793.

8. P. W. Schindler, in Equilibrium Concepts in Natural Water Systems, AMERICAN CHEMICAL SOCIETY, 1967, vol. 67, ch. 9, pp. 196-221.

9. A. E. Hixon and B. A. Powell, Observed Changes in the Mechanism and Rates of Pu(V) Reduction on Hematite As a Function of Total Plutonium Concentration, Environmental Science \& Technology, 2014, 48, 9255-9262.

10. B. A. Powell, Z. R. Dai, M. Zavarin, P. H. Zhao and A. B. Kersting, Stabilization of plutonium nano-colloids by epitaxial distortion on mineral surfaces, Environmental Science \& Technology, 2011, 45, 2698-2703.

11. K. Reed, A. Cormack, A. Kulkarni, M. Mayton, D. Sayle, F. Klaessig and B. Stadler, Exploring the properties and applications of nanoceria: is there still plenty of room at the bottom?, Environ. Sci.: Nano, 2014, 1, 390-405.

12. L. Soderholm, P. M. Almond, S. Skanthakumar, R. E. Wilson and P. C. Burns, The structure of the Plutonium oxide nanocluster $\mathrm{Pu}_{38} \mathrm{O}_{56} \mathrm{Cl}_{54}\left(\mathrm{H}_{2} \mathrm{O}\right)_{(8)}{ }^{(14-)}$, Angewandte Chemie-International Edition, 2008, 47, 298-302.

13. D. A. Costanzo, R. E. Biggers and J. T. Bell, Plutonium polymerization.1. Spectrophotometric study of polymerization of plutonium(IV), Journal of Inorganic \& Nuclear Chemistry, 1973, 35, 609-622.

14. U. Kaplan, S. Amayri, J. Drebert, A. Rossberg, D. Grolimund and T. Reich, Geochemical Interactions of Plutonium with Opalinus Clay Studied by Spatially Resolved Synchrotron Radiation Techniques, Environmental Science \& Technology, 2017, 51, 7892-7902.

15. J. Rothe, C. Walther, M. A. Denecke and T. Fanghanel, XAFS and LIBD investigation of the formation and structure of colloidal Pu(IV) hydrolysis products, Inorganic Chemistry, 2004, 43, 4708-4718.

16. V. Neck and J. I. Kim, Solubility and hydrolysis of tetravalent actinides, Radiochimica Acta, 2001, 89, 1-16.

17. G. E. Sigmon and A. E. Hixon, Extension of the Plutonium Oxide Nanocluster Family to Include \{Pu-16\} and $\{\mathrm{Pu}-22\}$, Chemistry-a European Journal, 2019, 25, 2463-2466.

18. T. W. Newton, D. E. Hobart and P. D. Palmer, The formation of Pu(IV) colloid by the alphareduction of $\mathrm{Pu}(\mathrm{V})$ or $\mathrm{Pu}(\mathrm{VI})$ in aqueous solutions, Radiochimica Acta, 1986, 39, 139-147. 
19. I. R. Triay, D. E. Hobart, A. J. Mitchell, T. W. Newton, M. A. Ott, P. D. Palmer, R. S. Rundberg and J. L. Thompson, Size determinations of plutonium colloids using autocorrelation photon spectroscopy, Radiochimica Acta, 1991, 52-3, 127-131.

20. P. Thiyagarajan, H. Diamond, L. Soderholm, E. P. Horwitz, L. M. Toth and L. K. Felker, Plutonium(IV) polymers in aqueous and organic media, Inorganic Chemistry, 1990, 29, 19021907.

21. D. Rai and J. L. Swanson, Properties of plutonium(IV) polymer of environmental importance, Nuclear Technology, 1981, 54, 107-112.

22. E. Dalodiere, M. Virot, V. Morosini, T. Chave, T. Dumas, C. Hennig, T. Wiss, O. D. Blanco, D. K. Shuh, T. Tyliszcak, L. Venault, P. Moisy and S. I. Nikitenko, Insights into the sonochemical synthesis and properties of salt-free intrinsic plutonium colloids, Scientific Reports, 2017, 7.

23. P. Zhao, M. Zavarin, Z. Dai and A. B. Kersting, Pu Sorption, Desorption and Intrinsic Colloid Stability under Granitic Chemical Conditions. United States: N. p., 2014. Web. doi:10.2172/1169859., Report LLNL-TR-659761, Lawrence Livermore National Lab. (LLNL), Livermore, CA (United States), 2014.

24. S. Mourdikoudis, R. M. Pallares and N. T. K. Thanh, Characterization techniques for nanoparticles: comparison and complementarity upon studying nanoparticle properties, Nanoscale, 2018, 10, 12871-12934.

25. F. Tao and P. A. Crozier, Atomic-scale observations of catalyst structures under reaction conditions and during catalysis, Chemical Reviews, 2016, 116, 3487-3539.

26. R. J. Batrice, J. N. Wacker and K. E. Knope, in Experimental and Theoretical Approaches to Actinide Chemistry, eds. J. K. Gibson and W. A. Jong, 2018, DOI: 10.1002/9781119115557.ch2, pp. 53-127.

27. A. Y. Romanchuk, T. V. Plakhova, A. V. Egorov, T. B. Egorova, P. V. Dorovatovskii, Y. V. Zubavichus, A. A. Shiryaev and S. N. Kalmykov, Redox-mediated formation of plutonium oxide nanoparticles, Dalton Transactions, 2018, 47, 11239-11244.

28. X. Beaudoux, M. Virot, T. Chave, G. Leturcq, G. Jouan, L. Venault, P. Moisy and S. I. Nikitenko, Ultrasound-assisted reductive dissolution of $\mathrm{CeO}_{2}$ and $\mathrm{PuO}_{2}$ in the presence of Ti particles, Dalton Transactions, 2016, 45, 8802-8815.

29. V. Morosini, T. Chave, M. Virot, P. Moisy and S. I. Nikitenko, Sonochemical water splitting in the presence of powdered metal oxides, Ultrasonics Sonochemistry, 2016, 29, 512-516.

30. D. H. Everett, Manual of Symbols and Terminology for Physicochemical Quantities and Units, Appendix II: Definitions, Terminology and Symbols in Colloid and Surface Chemistry.Journal, 1972, 31, 577.

31. R. E. Wilson, S. Skanthakumar and L. Soderholm, Separation of Plutonium Oxide Nanoparticles and Colloids, Angewandte Chemie-International Edition, 2011, 50, 1123411237.

32. B. Sitaud, P. L. Solari, S. Schlutig, I. Llorens and H. Hermange, Characterization of radioactive materials using the MARS beamline at the synchrotron SOLEIL, Journal of Nuclear Materials, 2012, 425, 238-243.

33. M. Doucet, J. H. Cho, G. Alina, J. Bakker, W. Bouwman, P. Butler, K. Campbell, M. Gonzales, R. Heenan, A. Jackson, P. Juhas, S. King, P. Kienzle, J. Krzywon, A. Markvardsen, T. Nielsen, L. O'Driscoll, W. Potrzebowski, R. Ferraz Leal, T. Richter, P. Rozycko, T. Snow and A. Washington, SasView version 4.2.Journal, 2018, DOI: 10.5281/zenodo.1412040.

34. B. Ravel and M. Newville, ATHENA, ARTEMIS, HEPHAESTUS: data analysis for X-ray absorption spectroscopy using IFEFFIT, Journal of Synchrotron Radiation, 2005, 12, 537-541.

35. J. J. Rehr, J. J. Kas, M. P. Prange, A. P. Sorini, Y. Takimoto and F. Vila, Ab initio theory and calculations of X-ray spectra, Comptes Rendus Physique, 2009, 10, 548-559.

36. L. Bonato, M. Virot, E. Dalodière, T. Dumas, A. Mesbah, O. Dieste Blanco, T. Wiss, D. Prieur, A. Rossberg, L. Venault, P. Moisy and S. I. Nikitenko, Probing the local structure of nanoscaled actinide oxides: a comparison between $\mathrm{PuO}_{2}$ and $\mathrm{ThO}_{2}$ nanoparticles rules out $\mathrm{PuO}_{2+x}$ hypothesis Nanoscale Adv., 2020, DOI: 10.1039/C9NA00662A. 
37. K. Takao, S. Takao, A. C. Scheinost, G. Bernhard and C. Hennig, Formation of Soluble Hexanuclear Neptunium(IV) Nanoclusters in Aqueous Solution: Growth Termination of Actinide(IV) Hydrous Oxides by Carboxylates, Inorganic Chemistry, 2012, 51, 1336-1344.

38. C. Tamain, T. Dumas, D. Guillaumont, C. Hennig and P. Guilbaud, First Evidence of a WaterSoluble Plutonium(IV) Hexanuclear Cluster, European Journal of Inorganic Chemistry, 2016, DOI: 10.1002/ejic.201600656, 3536-3540.

39. C. Walther, H. R. Cho, C. M. Marquardt, V. Neck, A. Seibert, J. I. Yun and T. Fanghanel, Hydrolysis of plutonium(IV) in acidic solutions: no effect of hydrolysis on absorption-spectra of mononuclear hydroxide complexes, Radiochimica Acta, 2007, 95, 7-16.

40. D. W. Ockenden and G. A. Welch, The preparation and properties of some plutonium compounds.5. Colloidal quadrivalent plutonium, Journal of the Chemical Society, 1956, DOI: 10.1039/jr9560003358, 3358-\&.

41. D. Cohen, The absorption spectra of plutonium ions in perchloric acid solutions, Journal of Inorganic \& Nuclear Chemistry, 1961, 18, 211-218.

42. L. Boldon, F. Laliberte and L. Liu, Review of the fundamental theories behind small angle Xray scattering, molecular dynamics simulations, and relevant integrated application, Nano Rev, 2015, 6, 25661-25661.

43. O. Glatter and O. Kratky, Small angle x-ray scattering, Academic Press, London; New York, 1982.

44. T. Li, A. J. Senesi and B. Lee, Small Angle X-ray Scattering for Nanoparticle Research, Chemical Reviews, 2016, 116, 11128-11180.

45. F. Nallet, Introduction à la diffusion aux petits angles, La Grande Motte, 2009.

46. T. V. Plakhova, A. Y. Romanchuk, S. M. Butorin, A. D. Konyukhova, A. V. Egorov, A. A. Shiryaev, A. E. Baranchikov, P. V. Dorovatovskii, T. Huthwelker, E. Gerber, S. Bauters, M. M. Sozarukova, A. C. Scheinost, V. K. Ivanov, S. N. Kalmykov and K. O. Kvashnina, Towards the surface hydroxyl species in $\mathrm{CeO}_{2}$ nanoparticles, Nanoscale, 2019, DOI: 10.1039/c9nr06032d.

47. L. Amidani, T. V. Plakhova, A. Y. Romanchuk, E. Gerber, S. Weiss, A. Efimenko, C. J. Sahle, S. M. Butorin, S. N. Kalmykov and K. O. Kvashnina, Understanding the size effects on the electronic structure of $\mathrm{ThO}_{2}$ nanoparticles, Physical Chemistry Chemical Physics, 2019, 21, 10635-10643.

48. A. I. Abdel-Fattah, D. X. Zhou, H. Boukhalfa, S. Tarimala, S. D. Ware and A. A. Keller, Dispersion stability and electrokinetic properties of intrinsic plutonium colloids: implications for subsurface transport, Environmental Science \& Technology, 2013, 47, 5626-5634.

49. H. K. Roobottom, H. D. B. Jenkins, J. Passmore and L. Glasser, Thermochemical radii of complex ions, Journal of Chemical Education, 1999, 76, 1570-1573.

50. T. Vitova, I. Pidchenko, D. Fellhauer, T. Pruessmann, S. Bahl, K. Dardenne, T. Yokosawa, B. Schimmelpfennig, M. Altmaier, M. Denecke, J. Rothe and H. Geckeis, Exploring the electronic structure and speciation of aqueous and colloidal Pu with high energy resolution XANES and computations, Chemical Communications, 2018, 54, 12824-12827.

51. D. Hudry, C. Apostolidis, O. Walter, A. Janssen, D. Manara, J. C. Griveau, E. Colineau, T. Vitova, T. Prussmann, D. Wang, C. Kubel and D. Meyer, Ultra-small plutonium oxide nanocrystals: an innovative material in plutonium science, Chemistry-a European Journal, 2014, 20, 10431-10438.

52. E. Dalodière, M. Virot, T. Dumas, D. Guillaumont, M.-C. Illy, C. Berthon, L. Guerin, A. Rossberg, L. Venault, P. Moisy and S. I. Nikitenko, Structural and magnetic susceptibility characterization of $\mathrm{Pu}(\mathrm{v})$ aqua ion using sonochemistry as a facile synthesis method, Inorganic Chemistry Frontiers, 2018, 5, 100-111.

53. C. Walther, J. Rothe, B. Brendebach, M. Fuss, M. Altmaier, C. M. Marquardt, S. Büchner, H.-R. Cho, J.-I. Yun and A. Seibert, New insights in the formation processes of $\mathrm{Pu}(\mathrm{IV})$ colloids, Radiochimica Acta \$V 97, 2009.

54. K. O. Kvashnina, S. M. Butorin, P. Martin and P. Glatzel, Chemical State of Complex Uranium Oxides, Physical Review Letters, 2013, 111, 253002. 
55. K. O. Kvashnina, H. C. Walker, N. Magnani, G. H. Lander and R. Caciuffo, Resonant x-ray spectroscopy of uranium intermetallics at the M-4,M-5 edges of uranium, Physical Review $B$, 2017, 95.

56. M. Hunault, G. Lelong, L. Cormier, L. Galoisy, P. L. Solari and G. Calas, Speciation Change of Uranyl in Lithium Borate Glasses, Inorganic Chemistry, 2019, 58, 6858-6865.

57. C. Ekberg, K. Larsson, G. Skarnemark, A. Odegaard-Jensen and I. Persson, The structure of plutonium(IV) oxide as hydrolysed clusters in aqueous suspensions, Dalton Transactions, 2013, 42, 2035-2040.

58. S. D. Conradson, B. D. Begg, D. L. Clark, C. Den Auwer, F. J. Espinosa-Faller, P. L. Gordon, N. J. Hess, R. Hess, D. W. Keogh, L. A. Morales, M. P. Neu, W. Runde, C. D. Tait, D. K. Veirs and P. M. Villella, Speciation and unusual reactivity in PuO2+x, Inorganic Chemistry, 2003, 42, 37153717.

59. S. D. Conradson, B. D. Begg, D. L. Clark, C. den Auwer, M. Ding, P. K. Dorhout, F. J. EspinosaFaller, P. L. Gordon, R. G. Haire, N. J. Hess, R. F. Hess, D. W. Keogh, G. H. Lander, D. Manara, L. A. Morales, M. P. Neu, P. Paviet-Hartmann, J. Rebizant, V. V. Rondinella, W. Runde, C. D. Tait, D. K. Veirs, P. M. Villella and F. Wastin, Charge distribution and local structure and speciation in the $\mathrm{UO} 2+\mathrm{x}$ and $\mathrm{PuO} 2+\mathrm{x}$ binary oxides for $\mathrm{x}<=0.25$, Journal of Solid State Chemistry, 2005, 178, 521-535.

60. P. Martin, S. Grandjean, M. Ripert, M. Freyss, P. Blanc and T. Petit, Oxidation of plutonium dioxide: an X-ray absorption spectroscopy study, Journal of Nuclear Materials, 2003, 320, 138-141.

61. P. Martin, S. Grandjean, M. Ripert, M. Freyss, P. Blanc and T. Petit, Oxidation of plutonium dioxide: an X-ray absorption spectroscopy study, Journal of Nuclear Materials, 2003, 320, 138-141.

62. M. Altmaier, X. Gaona and T. Fanghänel, Recent Advances in Aqueous Actinide Chemistry and Thermodynamics, Chemical Reviews, 2013, 113, 901-943.

63. A. Kuzmin and J. Chaboy, EXAFS and XANES analysis of oxides at the nanoscale, IUCrJ, 2014, 1, 571-589.

64. C. Hennig, Evidence for double-electron excitations in the L-3-edge x-ray absorption spectra of actinides, Physical Review B, 2007, 75.

65. L. Chatelain, R. Faizova, F. Fadaei-Tirani, J. Pecaut and M. Mazzanti, Structural Snapshots of Cluster Growth from $\{\mathrm{U}-6\}$ to $\{\mathrm{U}-38\}$ During the Hydrolysis of UCl4, Angewandte ChemieInternational Edition, 2019, 58, 3021-3026.

66. N. P. Martin, C. Volkringer, P. Roussel, J. Marz, C. Hennig, T. Loiseau and A. Ikeda-Ohno, \{Np38\} clusters: the missing link in the largest poly-oxo cluster series of tetravalent actinides, Chemical Communications, 2018, 54, 10060-10063.

67. K. E. Knope and L. Soderholm, Plutonium(IV) Cluster with a Hexanuclear Pu-6(OH)(4)O-4 (12+) Core, Inorganic Chemistry, 2013, 52, 6770-6772.

68. A. I. Frenkel, C. W. Hills and R. G. Nuzzo, A view from the inside: Complexity in the atomic scale ordering of supported metal nanoparticles, Journal of Physical Chemistry B, 2001, 105, 12689-12703.

69. A. I. Frenkel, C. W. Hills and R. G. Nuzzo, A View from the Inside: Complexity in the Atomic Scale Ordering of Supported Metal Nanoparticles, The Journal of Physical Chemistry B, 2001, 105, 12689-12703. 